\title{
Using Telephone Education to Decrease Fasting Blood Glucose Prior to Surgery
}

Christine Mott

Follow this and additional works at: https://researchrepository.wvu.edu/etd

\section{Recommended Citation}

Mott, Christine, "Using Telephone Education to Decrease Fasting Blood Glucose Prior to Surgery" (2017). Graduate Theses, Dissertations, and Problem Reports. 6272.

https://researchrepository.wvu.edu/etd/6272

This Dissertation is protected by copyright and/or related rights. It has been brought to you by the The Research Repository @ WVU with permission from the rights-holder(s). You are free to use this Dissertation in any way that is permitted by the copyright and related rights legislation that applies to your use. For other uses you must obtain permission from the rights-holder(s) directly, unless additional rights are indicated by a Creative Commons license in the record and/ or on the work itself. This Dissertation has been accepted for inclusion in WVU Graduate Theses, Dissertations, and Problem Reports collection by an authorized administrator of The Research Repository @ WVU.

For more information, please contact researchrepository@mail.wvu.edu. 
Using Telephone Education to Decrease Fasting Blood Glucose Prior to Surgery

Christine Mott MSN, APRN, FNP-BC

Doctoral Capstone Project submitted to the School of Nursing at West Virginia University in partial fulfillment of the requirements for the degree of

Doctor of Nursing Practice

Jennifer Mallow, Ph.D., Chair

Kendra Barker, DNP

Renee Schwertfeger, MSN

Department of Nursing

Morgantown, West Virginia

2017

Keywords: Type 2 diabetes, telephone intervention, surgery, and preoperative glycemic control. 


\begin{abstract}
Background: Uncontrolled diabetes during the perioperative period can result in increased postoperative infections, increased length of stay, increased ICU admissions, increased risk of myocardial infarction, stroke, and mortality. In addition, mortality rates of patients with diabetes are likely to be up to five times higher than patients without diabetes. Postoperative infections account for $66 \%$ of complications and one quarter of perioperative deaths. As a result of these findings, it is imperative that patients with diabetes maintain glycemic control in order to minimize infection, postoperative complications, and improve surgical outcomes.
\end{abstract}

Objective: The objective of the pilot project was to determine if an APRN telephone follow-up call would decrease fasting glucose levels the day of surgery for patients with uncontrolled Type 2 diabetes based on Kotter's change model. The change process involved patients with $\mathrm{HgA} 1 \mathrm{c}$ over $7 \%$ receiving an APRN follow-up telephone call. The telephone intervention provided evidence based education on 7 self-care behaviors essential for self-management of diabetes. Evaluation of the pilot project was based on fasting glucose levels the day of surgery and amount of time to make follow-up calls. Methods: The PICO question that guided this review was, "In adult surgical patients with Type 2 diabetes and elevated $\mathrm{HgAlc}>7 \%$, does patient education via telephone intervention compared to usual care, result in decreasing fasting blood glucose the day of surgery?" After searching the most pertinent articles, substantial evidence was found to support the practice change. Seventeen articles were obtained for inclusion, two systematic reviews, fourteen random controls, and one quasi-experimental. The intervention for this pilot project included diabetes education via a telephone follow-up call using the AADE7, which is an evidence based and patient centered framework of seven self-care behaviors that are essential for effective self-management of diabetes. A SMART plan provided guidance for development of the pilot project and the practice change was guided by Kotter's change model. Fifty participants were included in the pilot project. Twenty-five participants were randomly assigned to receive the intervention and twenty-five participants were randomly assigned to the control group.

Results: The follow-up APRN telephone call was done with 25 participants in the intervention group and 25 in the control group. Both groups had a reduction in the mean post-intervention glucose level from the random preoperative glucose levels. One-way ANOVA determined that there was no statistical difference between the control and intervention group $p=0.668$. Although results were not statistically different, four participants in the intervention group postponed surgery, perhaps preventing an adverse outcome. Conversely, all 25 participants in the control group completed their surgery. Discussion: Although the findings from this pilot project were not statistically significant, there may be some clinical significance in four participants choosing to delay surgery and potentially preventing adverse outcomes associated with hyperglycemia. Findings from the literature support an APRN follow-up telephone call for patients with uncontrolled Type 2 diabetes. Optimization of patients with uncontrolled diabetes is crucial in order to improve negative surgical outcomes associated with hyperglycemia. 


\section{Acknowledgements}

First I would like to start off by thanking my husband Ken for all of his love and support during this journey. I would not have been able to complete this journey without you. You stepped up during my absence and for that I'm grateful. I'm also grateful for my children Kayla and Konnor. You make me want to strive to be the best and I hope my dedication and drive inspires you to believe in yourself and know that you can achieve anything in life. I would also like to thank my best friend Terri Marchischak. Without your support and friendship I would never have accomplished everything that I have done. You have always pushed me to go beyond what I could have imagined for myself academically. Finally, I would like to thank my family for always believing in me and only wanting the best for me. My twin sister Crystal Foreman has been there to support me during this process. My parents Kay and Gordon Martin have always encouraged me to reach for the stars. My sister Kim Boehman and Mike Martin also provided support and encouragement.

Professional I would like to thank Dr. Jen Mallow. It has been a pleasure to have your guidance and friendship. You pushed me to excel and believed in my ability to achieve excellence. I would also like to thank Dr. Kendra Barker and Renee Schwertfeger who were part of my committee. Your guidance and feedback along with knowledge was a source of value for me and my project. I value your expertise and friendships.

Finally, I would like to thank the staff in the Preoperative Evaluation Center and WVU Medicine. Several members of the healthcare team played a valuable role. Tracy Brinegar played a key role in the project, along with the medical assistants, RNs, and 
APRNs. I could not have asked to have a better group of colleagues. A special thanks to Kaneetha Davis and Beth Stepak who were the lead RNs and helped to consent participants. You both were willing to help out and do whatever was needed to make the project a success. To the APRNs in the PEC Monique Bandy, Patty Hermosilla, Stacy Maltese, Terri Marcischak, Linda Metcalfe, Jen Molina, Janae Sherer, Billie Vance, Kym Wallace, Joy Williams, and Cindy Zemerick. You were instrumental in helping me to achieve this pilot study and recruiting participants. I feel honored to work with such a wonderful group of advanced practice providers. This project was truly a group effort and I appreciated everyone's willingness to be involved with the pilot study. 
Acknowledgements

Table of Contents

Introduction

Background

Problem Statement

Purpose of Project

Significance of Proposed Project 10

Literature Review

Methodology and Search Strategy 13

$\begin{array}{ll}\text { Literature Review } & 16\end{array}$

$\begin{array}{ll}\text { Literature Review Synthesis } & 18\end{array}$

Literature Review Discussion $\quad 26$

$\begin{array}{ll}\text { Theoretical Framework } & 28\end{array}$

$\begin{array}{ll}\text { Project } & 29\end{array}$

Design of Evidence-Based Project/Intervention Plan $\quad 30$

Feasibility Analysis $\quad 31$

Resources $\quad 32$

$\begin{array}{ll}\text { Needs Assessment } & 34\end{array}$

Organization’s Strategic Plan 35

Evidence of Key Site Support 39

Measureable Project Objectives $\quad 40$

Measurement Tools 41 
GLUCOSE PRIOR TO SURGERY

Evaluation Plan 41

Results 45

Sample $\quad 45$

Evaluation of Goals $\quad 46$

Discussion and Recommendations 53

Change Model Framework Results 53

Site Recommendations $\quad 60$

$\begin{array}{ll}\text { Application to other settings } & 60\end{array}$

Discussion Project Process and Outcomes 61

Attainment of DNP Essentials 63 


\section{Index of Appendices}

Appendix A

Capstone Budget Plan

67

Appendix B

Letter of Support WVU Medicine

69

Appendix C

SMART Work Plan

70

Appendix D

Script

75

Appendix E

Table 1 Demographics

78

Table 2 Descriptive Continuous Data Both Groups

79

Table 3 Test of Homogeneity of Variance

79

Table 4 ANOVA Results

80

Reference

81 


\section{Introduction}

Hyperglycemia during surgery can lead to poor clinical outcomes (Loh-Trivedi, 2011). The aim of this Capstone project report was to identify if an advanced practice registered nurse (APRN) follow-up call for patients with uncontrolled diabetes would decrease glucose levels the day of surgery. The structure of this Capstone project report paper includes background information about the impact of diabetes on the surgical patient, problem statement, purpose of the project, and the significance of the project. This will be followed by an extensive review and synthesis of the literature on telehealth interventions for improving glycemic control. Next will be a brief discussion of Kotter's practice change model. This will be followed by a discussion of the project, measurable project objectives, evaluation of the project, and results of the project. In addition, discussion of support of theoretical framework will be provided along with recommendations. Finally, the project report will conclude with the discussion of how the DNP essentials were attained.

\section{Background}

\section{General background information}

Approximately $12.6 \%$ of the United States population is affected by diabetes mellitus (CDC, 2015). Another 3\% of Americans are unaware that they have diabetes (CDC, 2015). Type 2 diabetes accounts for up to ninety-five percent of cases of diabetes and results when the body has an inability to utilize and produce insulin needed to decrease glucose (CDC, 2011). Patients with Type 2 diabetes are at an increased risk for 
GLUCOSE PRIOR TO SURGERY

micro and macro vascular complications (CDC, 2011). These complications increase the risk of considerable long-term morbidity and increased death (Killilea, 2002).

Patients with diabetes face several challenges and risks compared to patients without diabetes (Plodkowki \& Edelman, 2001). Patients with diabetes have an inability to balance insulin and other hormones (Plodkowki \& Edelman, 2001). Undergoing surgery and anesthesia creates a neuroendocrine response to stress, which then releases the hormones that cause an increase in glucose and an increase in catabolism (Plodkowki \& Edelman, 2001). The degree of response to these hormones during and after surgery depends on several factors related to the type and severity of surgery and other factors like infections, hypervolemia, and acidosis (Plodkowki \& Edelman, 2001). Patients without diabetes are able to increase insulin production and maintain glycemic control during surgical intervention, unlike those patients with diabetes who are unable to compensate for glycemic excursions (Plodkowki \& Edelman, 2001). Patients with Type 2 diabetes who are unable to compensate are at risk for developing hyperglycemic hyperosmolar nonketotic syndrome (HHNK) and diabetic ketoacidosis (Plodkowki \& Edelman, 2001). Patients with diabetes undergoing surgery face several challenges and risks that are not associated with patients without diabetes (Plodkowki \& Edelman, 2001).

People of West Virginia (WV) face several risk factors such as low socioeconomic status, lack of education, climate, geography, and decrease health literacy (WV DHHR, 2009). Social and physical risk factors put the residents of WV at a higher risk of developing diabetes. Risk of diabetes is higher in households that have an income of less than $\$ 15,000$ per year (WV DHHR, 2009). In fact, one out of five WV residents 
GLUCOSE PRIOR TO SURGERY

with an annual income of less than $\$ 15,000$ a year had diabetes (WV DHHR, 2009). The median household income for residents of WV was $\$ 40,400$ (US Census Bureau, 2013). In West Virginia 17.6\% of residents were below the poverty level (US Census Bureau, 2013). Lack of education also seems to play a role; $20 \%$ of WV residents in 2007 did not have a high school education and had diabetes (WV DHHR, 2009). In WV, $83.4 \%$ of residents over the age of 25 are high school graduates and $17.9 \%$ of those have earned a bachelor's degree or higher (US Census Bureau, 2013). Diabetes is also found to be higher among those with other chronic diseases such as cardiovascular disease and hypertension (WV DHHR, 2009). In addition, those who are obese, inactive, and have high cholesterol levels also have a higher prevalence of diabetes (WV DHHR, 2009). Obesity is prevalent in WV. In the United States, WV along with Mississippi had the highest obesity rates in the country at greater than $35 \%$ (CDC, 2011). Poverty, access to food, inability to exercise, and lack of education could all be associated with obesity.

The population of interest for this Capstone project was adult patients with uncontrolled Type 2 diabetes undergoing a surgical intervention at a surgery center in North Central West Virginia. Data from the US Census Bureau shows the differences of WV residents compared to the national averages. In 2013 females accounted for $50.6 \%$ of the adult population in WV (US Census Bureau, 2013). Compared to the rest of the United States, WV has more people over the age of 65; the national average for the US is $14.1 \%$ over the age of 65 and $17.3 \%$ for WV (US Census Bureau, 2013). West Virginia does not have a great variety of racial diversity with $93.8 \%$ of the population being white (US Census Bureau, 2013). American Indians make up only $0.2 \%$, while African 
GLUCOSE PRIOR TO SURGERY

Americans make up $3.6 \%$ of the population followed by the Hispanic population at $1.4 \%$ (US Census Bureau, 2013).

Most of the healthcare costs in WV are funded through government and private insurers. In fact, almost half of the population had insurance provided by employers. Almost half (47\%) of the residents in WV have insurance provided by employers. Another $2 \%$ is provided by private insurers, $17 \%$ Medicaid, $17 \%$ Medicare, and $15 \%$ uninsured (Kaiser Family Foundation, 2014).

The people of WV and Appalachia face unique challenges. The state of WV is the only state that is entirely within Appalachia (Smith \& Tessaro, 2005). The geography and climate of Appalachia can make it difficult for patients with diabetes to be physically active due to challenging weather, rough terrain, and lack of interstate transportation systems. In addition, many areas do not have gyms and if they do, most people would not be able to afford the high cost of monthly memberships.

The management of diabetes includes dietary modifications, lifestyle management, routine visits for testing and medications, and increased physical activity (Tessaro, Smith, \& Rye, 2005). Living in Appalachia places many people in this area at risk for social and health disparities, which include poverty, access to care, shortage of providers, lack of employment, and education (Tessaro, Smith, \& Rye, 2005). Poverty among West Virginians plays a critical role and often dictates decisions and behaviors (Tessaro, Smith, \& Rye, 2005). Those with lower socioeconomic status have greater rates of morbidity and mortality while those with higher socioeconomic status are more likely to adopt healthier lifestyles, have access to better nutrition, housing, and medical care (Foulk, Carroli, \& Wood, 2001). Patients with diabetes who are poor are more 
GLUCOSE PRIOR TO SURGERY

likely to be hospitalized and have more severe disease than those with higher incomes

(Foulk, Carroli, \& Wood, 2001). Often patients will adopt creative ways of dealing with their diabetes due to inability to access care, limited availability of health care resources, transportation, and education (Tessaro, Smith, \& Rye, 2005). This is also true in regards to nutrition, including availability of healthy food choices.

Health literacy also plays a role in the management of diabetes. Health literacy related to diabetes involves understanding of glycemic control, knowledge about the disease, and self-care behaviors that will have an impact on outcomes of the disease (Cavanaugh, 2012). People who feel they have a low level of medical knowledge may also lack the willingness to discuss medical needs outside of the family (Coyne, DemianPopesuc, \& Friend, 2006).

Appalachian residents have a distrust of physicians, and especially foreign providers, and often see medical advice as the last option (Coyne, Demian-Popesuc, \& Friend, 2006). Many Appalachians feel disgruntled about seeing foreign physicians and do not develop a trusting relationship (Coyne, Demian-Popesuc, \& Friend, 2006). This lack of trust often leads to patients being non-adherent with medical recommendations.

Understanding the culture and disparities faced by the people of Appalachia is an important factor in the prevention and management of diabetes, along with influencing their abilities to provide self-care. Self-care has played an important role in health promotion of individuals and populations (Orem, 2001). In order for self-care to be promoted, the nurse must "understand the relationships among health beliefs, self-care, and basic conditioning factors, each of which are unique to individuals and cultural groups" (Slusher, Withrow-Fletcher, \& Hauser-Whitaker, 2010, p. 85). It is important to 
GLUCOSE PRIOR TO SURGERY

have an understanding of how Appalachian culture and beliefs impact health practices.

Some unique characteristics of Appalachian culture include lack of knowledge regarding diabetes and the perception regarding the risk of diabetes (Tessaro, Smith, \& Rye, 2005). People with diabetes in Appalachia feel a sense of blame or guilt, and often feel the diabetes was self-induced as a result of being lazy or eating too many sweet foods (Tessaro, Smith, \& Rye, 2005). These beliefs along with other factors such as geography, poverty, health illiteracy, and lack of education as well as health care providers place this population at risk for self-care deficits.

Understanding the needs and beliefs of the Appalachian population is key to compensating for the challenges faced. Since geography and transportation may be an issue, one method of providing interventions may be through the use of telehealth. Telehealth or telephone interventions have been found to be a valuable alternative to conventional interventions for patients with diabetes (Siriwardena et al., 2012). With telehealth, healthcare providers have the opportunity to play a valuable role in the delivery of education while identifying new ways to deliver care for patients with culturally specific needs.

Diabetes is major health concern in the US and WV. Understanding the risk factors, beliefs, demographics, unique factors, and characteristics is key to caring for certain populations. Healthcare providers need to be aware of importance of cultural influence and work to tailor interventions to meet the needs of the patients of Appalachia in order to provide care. Challenges within the population need to be identified and addressed in order to provide the highest level of care and improve patient outcomes. It 
GLUCOSE PRIOR TO SURGERY

is important for providers to understand the disparities that many people in WV face, and work to provide care to this population.

\section{Problem statement}

Uncontrolled diabetes during the perioperative period can result in increased postoperative infections, increased length of stay, increased ICU admissions, increased risk of myocardial infarction, stroke, and mortality (Perencevich et al., 2003). In addition, mortality rates of patients with diabetes are likely to be up to five times higher than patients without diabetes (Loh-Trivedi, 2011). Postoperative infections account for $66 \%$ of complications and one quarter of perioperative deaths (Loh-Trivedi, 2011). As a result of these findings, it is imperative that patients with diabetes maintain glycemic control in order to minimize infection and postoperative complications.

Currently in the preadmission testing unit (PAU) at the surgery center for this project, patients with Type 2 diabetes and $\mathrm{HgA} 1 \mathrm{c}$ levels above 7\% are not receiving any additional education or notification that their $\mathrm{HgA} 1 \mathrm{c}$ levels are elevated. As a result, most patients have not been aware of the results of their $\mathrm{HgAlc}$ levels. Often patients have the belief that if they have not received a call regarding lab results than they are within normal limits. Patients with uncontrolled diabetes undergoing surgical intervention need to be aware of the impact of uncontrolled glucose on surgical outcomes, as well as understand their role in self-management of their disease prior to surgery. It is important to understand the unique challenges faced by the people of WV and work to eliminate these health disparities. Providing an APRN telephone follow-up call may help to decrease some of the barriers to accessing care faced by this population. 
GLUCOSE PRIOR TO SURGERY

Current practice in the PAU does not address patients with elevated HgA1c levels unless their $\mathrm{HgA} 1 \mathrm{c}$ is over $10 \%$ and in this case surgeons are notified and elective surgeries may be postponed. With proper education and notification patients with elevated $\mathrm{HgA} 1 \mathrm{c}$ levels may be able to better manage their diabetes prior to surgical intervention. Therefore, some intervention needs to be done to address hyperglycemia among patients with diabetes prior to surgery. Since lab results are not available until the day after patients have left the PAU, results would be reviewed by the APRN the next business day. The plan for this intervention was that all patients with Type 2 diabetes and $\mathrm{HgA} 1 \mathrm{c}$ levels greater than 7\% would receive a telephone follow-up call from the APRN discussing results of $\mathrm{HgAlc}$ and impact on surgical outcomes. The plan included that patients with unknown diabetes and elevated $\mathrm{HgA1c}$ levels would be referred to their primary care provider and also receive a APRN follow-up call in which they would receive education on self management of their diabetes.

\section{Purpose of project}

The National Guideline Clearinghouse (NCG) recommends that perioperative patients with diabetes have a fasting glucose around 90-130 gm/dl the day of surgery and HgA1c of less than $7 \%$ in order to decrease surgical risks associated with diabetes (National Guideline Clearinghouse (NGC), 2011). In addition, the NGC also recommends that all patients with diabetes receive a HgAlc level and fasting glucose

prior to surgery (NCG, 2011). Patients with no history of diabetes should also receive a fasting glucose prior to surgery (NCG, 2011). Glycemic control has been shown to reduce the incidence of many of the complications associated with diabetes postoperatively (Loh-Trivedi, 2011). It is important that patients with diabetes maintain 
GLUCOSE PRIOR TO SURGERY

glycemic control prior to undergoing surgical intervention in order to improve surgical outcomes and decrease surgical complications.

During the preoperative assessment in PAU patients with diabetes have HgA1c levels drawn to assess glycemic control. All adult patients having surgery also have a random glucose level performed as a fingerstick in addition to routine vital signs; this is to help identify unknown patients with diabetes. Prior to this project, there was no intervention between assessment of elevated glycemic levels and the day of surgery. The proposed intervention required all patients with $\mathrm{HgA} 1 \mathrm{c}$ levels greater than $7 \%$ to receive a follow-up telephone call from the preadmission testing APRN. The APRN would discuss with the patients the results of their HgA1c levels. In addition, patients would receive education via telephone on specific self-management activities to improve glucose levels prior to surgery and thus, improve surgical outcomes. During this call, the APRN would follow an evidence-based script for self-management of diabetes and discuss postoperative complications that could occur if glycemic control was not obtained prior to surgery.

Optimization of surgical patients is the goal of the APRN assessing patients in the PAU. The APRNs are responsible for determining if surgical patients are adequately prepared and educated prior to surgical intervention. A focus of this assessment was glycemic control due to the impact on surgical outcomes. One potential evidence based practice change would involve education via a follow-up telephone call or telehealth. The evidence suggests such interventions may be a beneficial way to reach patients with uncontrolled diabetes and improve surgical outcomes. 
GLUCOSE PRIOR TO SURGERY

Telehealth is defined as the use of electronic information and telecommunication technologies, such as telephone interventions, to support long-distance clinical healthcare and patient and education via professional healthcare provider (Hebda \& Czar, 2012). Patients with uncontrolled diabetes can benefit from interventions involving telehealth in order to decrease HgAlc and glucose levels through education and follow-up support (Gray, Drayton-Brooks, \&Williamson, 2013). Patients have reported higher satisfaction with telehealth interventions verses conventional interventions, and perceived enhanced provider commitment to participating in care when receiving telehealth services (Siriwardena et al., 2012). Telehealth interventions have been found to be a valuable alternative to conventional interventions (Siriwardena et al., 2012). With telehealth, healthcare providers have the opportunity to play a valuable role in the delivery of education and in identifying new ways to deliver care. Education of patients on the impact of hyperglycemia and ways to self-manage the disease may help patients maintain glycemic control and reduce the risk of serious postoperative complications.

Patients with Type 2 diabetes are required to make daily choices in order to selfmanage the disease (Khunit et al., 2012). Making patients aware of the serious complications of hyperglycemia during the preoperative period may enhance selfmanagement of diabetes prior to surgery. Self-management of diabetes has played an important role in helping patients actively participate and take responsibility for their own self-management (Khunit et al., 2012). Additional self-management patient education from healthcare providers prior to surgery can lead to improved outcomes, decreased complications, and reduced cost associated with poor diabetes control (Killilea, 2002).

\section{Significance of proposed project}


GLUCOSE PRIOR TO SURGERY

The prevalence of patients with diabetes undergoing surgery has steadily increased over the years (Loh-Trivedi, 2011). As a result of this increase, the risk of serious postoperative complications has intensified, making appropriate preoperative management and assessment of patients with diabetes crucial (Loh-Trivedi, 2011). It is estimated that $25 \%$ of patients with diabetes will require surgical intervention over the course of their lifetime (Loh-Trivedi, 2011). Patients with diabetes have higher rates of mortality and infection over those without diabetes (Loh-Trivedi, 2011). It has been found that infection is responsible for one quarter of perioperative deaths (Loh-Trivedi, 2011). Risk of infection is increased in patients with diabetes because glucose levels over $250 \mathrm{mg} / \mathrm{dl}$ impair leukocyte chemotaxis and phagocytosis (Plodkowki \& Edelman, 2001). It is imperative that patients with diabetes maintain glycemic control in order to minimize the risk of postoperative infection. In addition to infection, studies have found patients with diabetes have an increased length of hospital stay postoperatively, increased ICU admissions, increased risk for myocardial infarctions, stroke, and an increased mortality among patients with hyperglycemia (Moitra \& Meiler, 2006).

Implementation of a nurse telephone follow-up call could potentially save thousands of healthcare dollars. This intervention has the potential to reduce length of stay and decrease intensive care units (ICU) admissions. In 2003, the Journal of American Medical Association conducted a research study, which found postoperative complications to be responsible for up to $22 \%$ of avoidable deaths (Zhan \& Miller, 2003). Of the surgical complications, postoperative infection remains the number one cause of patient mortality and healthcare cost (Perencevich et al., 2003). The cost of postoperative infection was estimated to increase length of hospital stay by seven days and add over 
GLUCOSE PRIOR TO SURGERY

$\$ 3,000$ worth of additional healthcare costs (Polk \& Christmas, 2000). Another retrospective study conducted at John Hopkins Health System acute care hospitals between 2007-2010 looked at surgical site infections and cost of complications (Shepard, et al., 2013). The healthcare cost associated with surgical site infections were staggering. The study found that patients with surgical site infections stayed almost five days longer (Shepard, et al., 2013). Not only did the patients stay longer, but they also had a 51.94\% chance of being readmitted versus $8.19 \%$ for patients without surgical site infections (Shepard, et al., 2013). Those patients with surgical site infections also had higher daily cost totals (Shepard, et al., 2013). Patients with surgical site infections are more likely to have increased ICU admission, are up to five time more likely to be readmitted to hospital for care, and have a mortality rate twice that of patients without postoperative infections (Kirkland, Briggs, Trivette, Wilkinson, \& Sexton, 1999). Patients with diabetes have a greater risk of postoperative infections, and therefore, controlling glucose prior to surgery could impact the risk of infections and increase healing of surgical wounds. Controlling diabetes preoperatively has been found to minimize infection and decrease complications in a variety of surgical patients (Loh-Trivedi, 2011).

It is evident that implementation of this intervention could increase savings by decreasing cost associated with postoperative complications of uncontrolled diabetes. Implementation of this intervention will also increase patient safety and improve patient care. Glycemic control of the surgical patient needs to be addressed during the preoperative evaluation. APRNs in preoperative evaluation center play a key role in educating patients and decreasing risk of postoperative complications. 


\section{Literature Review \& Synthesis}

\section{Methodology and search strategy}

A detailed search was conducted from March 5, 2016 to July 15, 2016 using the following data sources: National Guideline Clearinghouse, Cochrane Library, CINAHL, Google Scholar, and PubMed. Articles were excluded if they did not meet the following inclusion criteria: 1) adult 18 years and older, 2) related to PICO question, 3) randomized control trials or quasi-experimental trials, 4) Type 2 diabetes and 5) telephone intervention. This search was update on January 20, 2017 and no new additional relevant studies were found. The PICO question that guided this review was, "In adult surgical patients with Type 2 diabetes and elevated $\mathrm{HgAlc}>7 \%$, does patient education via telephone intervention compared to usual care, result in decreasing fasting blood glucose the day of surgery?" PubMed was searched with MESH terms of diabetes, then diabetes mellitus Type 2 and then subheading of surgery within the last 10 years and limited to human subjects yielded 868 results and yielded one study (Lee, Wyatt, Topliss, Walker, \& Stoney, 2014). The focus of the other 867 studies was on bariatric surgery for patients with Type 2 diabetes and those were therefore excluded. In addition, PubMed was searched with no limits for preoperative glycemic control and had 202 findings. The abstracts of 202 articles were reviewed and 39 abstracts met the inclusion criteria. After further review of the full text articles only one actually met the inclusion criteria (Garg, et al., 2014). The other 38 articles were excluded because they looked at surgical outcomes such as infection and mortality, perioperative management of patients with diabetes, 
GLUCOSE PRIOR TO SURGERY

hospital protocols, and were not RCT or quasi-experimental studies. CINAHL was also searched using keywords of diabetes and preoperative education and yielded 61 findings with one duplicate study found (Lee, Wyatt, Topliss, Walker, \& Stoney, 2014). All other relevant 60 findings were not RCT or quasi-experimental studies and focused on preoperative needs, diabetes protocols, and management of diabetes, therefore were excluded. Cochrane library was searched with no limits and key words diabetes and preoperative education. This search yielded six findings but all were excluded due to not meeting inclusion criteria. One article was related to bariatric surgery and the others were inpatient diabetes education. The National Guidelines Clearinghouse was searched using the keywords diabetes and preoperative education with limits placed for adult patients and from 2007-2015. This searches yielded 28 results, all of which were excluded due to not meeting inclusion criteria. The majority of findings focused on guidelines for diabetes care. Google Scholar was searched utilizing the following search terms: diabetes and "preoperative education" with custom search from 2006-2016. This search resulted in 700 findings, all of which were rejected due to not meeting criteria for PICO question and literature review. The majority of the findings related to preoperative education focused on anxiety and bariatric surgery. Additional searching was completed with the following keywords: Type 2 diabetes, telephone intervention, nurse follow-up intervention, blood glucose control, and glycemic control and telehealth. Search words were used in varying combinations. Limits were set to include published within the last ten years (May 2006-July 2016) due to saturation of evidence over the past 10 years, academic journals, and English language. CINAHL provided a total of 734 findings. Of those, 26 were reviewed with further evaluation and yielded one systematic review (Gray, 
GLUCOSE PRIOR TO SURGERY

Drayton-Brooks, \& Williamson, 2013). The other 25 were rejected due to not meeting inclusion criteria and most were not research studies. PubMed was again searched without limits and provided a total of thirteen findings using the key words: nurse telephone, telehealth, Type 2 diabetes, and intervention. There were two relevant findings: one RCT and one quasi-experimental (Kim, 2007 \& Zolfaghari et al., 2011). Three other articles met inclusion criteria but were excluded due to the studies not being completed. An additional article was found and met criteria but was already included in systematic review (Gray, Drayton-Brooks, \& Williamson, 2013). Google scholar provided 1,960 findings after limits were set for 10 years, and yielded six RCT (Aliha et al., 2013; Bell, Fonda, Walker, Schmidt, \& Vigersky, 2012; Graziano \& Gross, 2009; McMahon, Fonda, Gomes, Alexis, \& Conlin, 2012; Nesari, Zakerimoghadam, Rajab, Bassampour \& Faghihzadeh, 2010; \& Sacco, Malone, Morrison, Friedman, \& Wells, 2009) and one quasi experimental which was already found (Zolfaghari, et al., 2011). In addition, one systematic review was also found (Pare, Moqadem, Pineau, \& St-Hilaire, 2010). Forty-three full text articles were review but excluded due to not meeting inclusion criteria. Several articles were also excluded due to the intervention involving texting and transmission of daily glucose readings with cellular telephones. Additionally, the reference sections of all relevant articles were reviewed and found five RCTs to be included (Frosch, D., Uy, Ochoa, \& Mangione, 2011; Walker et al., 2011; Williams et al., 2012; Wolever et al., 2010; Yoon \& Kim, 2008). After searching the most pertinent articles, substantial evidence was found to support practice change. After review and evaluation of relevant evidence, seventeen articles were obtained for inclusion, two 
GLUCOSE PRIOR TO SURGERY

systematic reviews, fourteen random controls, and one quasi-experimental (See evidence table 1).

\section{Literature review}

Fourteen RCTs were critically appraised for internal validity utilizing the Scottish Intercollegiate Guideline Network (Scottish Intercollegiate Guideline Network [SIGN], 2013). The remaining quasi-experimental study was appraised for internal validity based on an appraisal worksheet (Larrabee, 2009). Results from all critical appraisals are located within the evidence table 1.

Two systematic reviews found that telehealth has a positive impact on decreasing HgA1c levels (Gray, Drayton-Brooks, \& Williamson, 2013 \& Pare, Moqadem, Pineau, \& St-Hilaire, 2010). One systematic review found six out of ten studies conducted by nurses showed a reduction in HgAlc levels (Gray, Drayton-Brooks, \& Williamson, 2013). The second systematic review focused on the impact of telemonitoring on chronic illnesses such as diabetes (Pare, Moqadem, Pineau, \& St-Hilaire, 2010). Twenty-four articles reviewed found a trend in better glycemic control with telemonitoring. Two large RCTs and thirteen other studies, which included 10 small RCT found positive outcomes on glycemic control with the use of telemonitoring (Pare, Moqadem, Pineau, \& StHilaire, 2010).

All fourteen studies found that the telehealth intervention led to decreased $\mathrm{HgAlc}$ levels from baseline (Aliha et al., 2013; Bell, Fonda, Walker, Schmidt, \& Vigersky, 2012; Frosch, D., Uy, Ochoa, \& Mangione, 2011; Graziano \& Gross, 2009; Kim, 2007; Lee, Wyatt, Topliss, Walker, \& Stoney, 2014; McMahon, Fonda, Gomes, Alexis, \& Conlin, 
GLUCOSE PRIOR TO SURGERY

2012; Nesari, Zakerimoghadam, Rajab, Bassampour \& Faghihzadeh, 2010; Sacco,

Malone, Morrison, Friedman, \& Wells, 2009; Walker et al., 2011; Williams et al., 2012;

Wolever et al., 2010; Yoon \& Kim, 2008; Zolfaghari, et al., 2011). In addition, one study looked at glucose levels the day of surgery during two phases (Garg, et al., 2014).

Statistically higher percentages of patients achieved target fasting glucose levels the day of surgery compared to the control group $(\mathrm{p}<0.05)$, control vs. phase 1 and $(<0.001)$ control vs. phase 2 (Lee, Wyatt, Topliss, Walker, \& Stoney, 2014). However, only eleven of the fourteen studies found a statistically significant difference in $\mathrm{HgAl}$ c levels (Aliha et al. 2013; Bell, Fonda, Walker, Schmidt, \& Vigersky 2012; Frosch, D., Uy, Ochoa, \& Mangione, 2011; Kim 2007; Lee, Wyatt, Topliss, Walker, \& Stoney, 2014; McMahon et al. 2012; Nesari, Zakerimoghadam, Rajab, Bassampour \& Faghihzadeh, 2010; Walker et al. 2011; Williams et al. 2012; Yoon \& Kim, 2008; Zolfaghari et al., 2011). The three studies that were not statistically significant still showed decreases in $\mathrm{HgAlc}$ levels from baseline but no significant difference between groups (Graziano \& Gross, 2009; Sacco, Malone, Morrison, Friedman, \& Wells, 2009; Wolever et al., 2010). All three of the studies did not have an intervention for the control other than usual care. For Graziano et al., usual care consisted of visits to the clinic every 2-3 months (Graziano \& Gross, 2009). During these visits patients were provided education and support by a team of diabetes specialists (Graziano \& Gross, 2009). The control group in the study by Sacco et al. also received usual care, which consisted of treatment by an endocrinologist every six months (Sacco, Malone, Morrison, Friedman, \& Wells, 2009). In the study conducted by Wolever et al., the participants in the control group received no other materials or communications from providers (Wolever et al., 2010). Wolever et al., did 
GLUCOSE PRIOR TO SURGERY

find that participants whose $\mathrm{HgA} 1 \mathrm{c}$ 's were over 7\% did significantly reduce their $\mathrm{HgA} 1 \mathrm{c}$ by $0.64 \%$ after 6 months of the intervention $(\mathrm{P}=.030$; Cohen $\mathrm{d}$ effect size $=.34)$ but this was not statistically different when analyzed with all participants in the intervention group, which included those patients who had HgA1c less than 7\% (Wolever et al., 2010).

\section{Literature review synthesis}

Two trials were conducted by Kim and associates at an 800 bed urban hospital in South Korea (Kim, 2007 \&Yoon \& Kim, 2008). Both of the trials had 50 or more participants (Kim, 2007 \&Yoon \& Kim, 2008). One study found that patients in the intervention group reduced $\mathrm{HgAlc}$ levels by $1.15 \%$, while those in the control group had an increase in $\mathrm{HgA} 1 \mathrm{c}$ levels by $0.07 \%(\mathrm{p}=0.005)(\mathrm{Kim}, 2007)$. The other study found that patients in the intervention had lower HgAlc levels over one year compared to the control group (Yoon \& Kim, 2008). The intervention group's HgA1c's were decreased by -1.32 while the control group was increased by +0.81 (Yoon $\&$ Kim, 2008).

Ten studies found that the participants of the intervention and control groups had similar characteristics at baseline (Bell, Fonda, Walker, Schmidt, \& Vigersky, 2012; Garg et al., 2016; Kim, 2007; McMahon et al., 2012; Nesari, Zakerimoghadam, Rajab, Bassampour \& Faghihzadeh, 2010; Sacco, Malone, Morrison, Friedman, \& Wells, 2009; Walker et al., 2011; Wolever et al., 2010; Yoon \& Kim, 2008; Zolfaghari et al., 2011). While four RCTs and one quasi-experimental study had many baseline characteristic similarities, there were some differences, which may have impacted the results of the findings. One study reported that the intervention group had worse renal function than the comparison group with estimated glomerular filtration rate 76.0 for intervention and 85.5 
GLUCOSE PRIOR TO SURGERY

for comparison (Williams et al., 2012). Two studies had significant differences in age. In the study by Williams et al., the mean age was 58.4 in the intervention group and age 56.4 for the control group. Seventy percent of the comparison group had secondary education versus $60 \%$ of the intervention group (Williams et al., 2012). In the study conducted by Frosch et al., the mean age of the control group was 54.3 years and 56.7 years for the experimental group ( $\mathrm{P}=$. 05) (Frosch, D., Uy, Ochoa, \& Mangione, 2011). All of these factors could impact the validity of the study and could be viewed as a weakness. Another threat to the validity of one study was the racial diversity of the groups. The intervention group had twice as many participants who reported nonwhite as ethnic status (Graziano \& Gross, 2009). In the study by Aliha et al., participants were similar in all characteristics except job type, number of years with diabetes, and fasting glucose levels (Aliha et al., 2013). Job status was found to be statistically significant with $\mathrm{p}$ value 0.037 . It was found that $81.8 \%$ of intervention group had public jobs status versus $18.2 \%$ in the control group (Aliha et al). Duration of diabetes was also statistically different with $\mathrm{p}$ value of 0.049 (Aliha et al). Duration of time with diabetes for intervention group was $7.1+/-4.8$ years versus $10.3+/-7.3$ years for the control group (Aliha et al). In addition, fasting glucose levels were also found to be statistically significant with $\mathrm{p}$ value of 0.002 between groups (Aliha et al). Fasting blood glucose among the intervention group was $182+/-51.9$ versus $144+/-40$ for control group (Aliha et al). Lee et al., did find a statistical difference in baseline $\mathrm{HgA} 1$ between the intervention (10.1\%) and the usual care group (7.2\%) $(\mathrm{p}<.001)$ (Lee, Wyatt, Topliss, Walker, \& Stoney, 2014). This could impact the results of the overall findings of the study. 
GLUCOSE PRIOR TO SURGERY

The length of time that the studies were conducted varied. Five studies (Aliha et al., 2013; Graziano \& Gross, 2009; Kim, 2007; Nesari, Zakerimoghadam, Rajab, Bassampour \& Faghihzadeh, 2010; \& Zolfaghari et al., 2011) ended at twelve weeks, four studies (Frosch, D., Uy, Ochoa, \& Mangione, 2011; Sacco, Malone, Morrison, Friedman, \& Wells, 2009; Williams et al., 2012; \& Wolever et al., 2010) ended at six months, and four studies (Bell, Fonda, Walker, Schmidt, \& Vigersky, 2012; McMahon et al., 2012; Walker et al., 2011; Yoon \& Kim, 2008) ended at twelve months. The length of time could have impacted the results of these studies since we know that it does take time for HgAlc levels to change.

In two of the studies, the intervention was done during a scheduled visit to the pre-operative clinic (Garg et al., 2016 \& Lee, Wyatt, Topliss, Walker, \& Stoney, 2014). These studies were different than the other telephone follow-up studies because the educational intervention was done in the clinic. One study performed the education in the clinic and then did a telephone follow-up call for those patients that were unable to receive the education during the clinic visit (Garg et al., 2016). Garg et al., found that there was no difference in glucose outcomes for those patients who were seen in clinic versus those who were contacted by the telephone, $88 \%$ had a glucose of less than 200 the day of surgery, compared to $85 \%$ who were seen by the nurse practitioner in the clinic (Garg et al., 2016). In the study by Lee et al., the patients were seen by the diabetes nurse, dietician, and endocrinologist during the preoperative visit and self-management education was provided (Lee, Wyatt, Topliss, Walker, \& Stoney, 2014). Postoperative HgA1c levels were significantly decreased with the intervention group by $1.9 \%(p<0.05)$ compared to the control group 1.2\% (Lee, Wyatt, Topliss, Walker, \& Stoney, 2014). 
GLUCOSE PRIOR TO SURGERY

Even though this education was not done by telephone, the results show that additional education is beneficial and could be done as a telephone follow-up call.

The length of follow-up varied from twelve weeks to twelve months. All four studies conducted over twelve months found that the telephone intervention significantly reduced HgA1c levels (Bell, Fonda, Walker, Schmidt, \& Vigersky, 2012; McMahon et al., 2012; Walker et al., 2011; Yoon \& Kim, 2008). Two studies conducted over six months found the telephone intervention significantly reduced $\mathrm{HgA} 1 \mathrm{c}$ levels from baseline (Frosch, D., Uy, Ochoa, \& Mangione, 2011 \& Williams et al., 2012). Two studies conducted over six months did not find any statistically significant difference between control and intervention, but did find a reduction in A1c levels from baseline (Sacco, Malone, Morrison, Friedman, \& Wells, 2009; \& Wolever et al., 2010). One study did find that there was a significant reduction of A1c for the intervention group of $0.64 \%$ over the 6 months with patients whose baseline A1c was over $7 \%(\mathrm{P}=.030$; Cohen $\mathrm{d}$ effect size $=.34$ ) but there was no significance between the groups (Wolever et al., 2010). Results from these findings support the need for further education for patients with uncontrolled glucose levels. The target population for this Capstone is patients with HgA1c levels over 7\%. Therefore, it can be said that excluding patients with diabetes who are well controlled would have changed the results of this study. Three studies found a statistically significant difference between control and intervention after 12 weeks (Aliha et al., 2013; Kim, 2007; Nesari, Zakerimoghadam, Rajab, Bassampour \& Faghihzadeh, 2010). Two additional studies conducted for twelve weeks did not show a significant difference in $\mathrm{HgAlc}$ levels between groups but did have a decrease in $\mathrm{HgA1c}$ from baseline (Graziano \& Gross, 2009 \& Zolfaghari et al., 2011). There remains a gap 
GLUCOSE PRIOR TO SURGERY

in the amount of time needed to have a significant change in $\mathrm{HgAl}$ c levels. The amount of time needed to change $\mathrm{HgAl}$ c levels could be a factor in the results of these studies.

There were also variations in delivery of the intervention. In five of the studies, the intervention was delivered by a nurse (Aliha et al., 2013; Frosch, D., Uy, Ochoa, \& Mangione, 2011; Kim, 2007; Nesari, Zakerimoghadam, Rajab, Bassampour \& Faghihzadeh, 2010; Zolfaghari et al., 2011). In the study by Bell et al., the intervention was delivered by a nurse practitioner (Bell, Fonda, Walker, Schmidt, \& Vigersky, 2012). Garg et al., had 2 phases the first phase the intervention was done by a physician and the second phase was done by two nurse practitioner (Garg, et al., 2016). Lee et al., and Yoon \& Kim both utilized an endocrinologist for the intervention, while Yoon \& Kim, used a nurse along with an endocrinologist (Lee, Wyatt, Topliss, Walker, \& Stoney, 2014 \& Yoon \& Kim, 2008). Walker et al. utilized health educators and McMahon et al., utilized certified diabetes educators to deliver the intervention (McMahon et al., 2012 \& Walker et al., 2011). Williams et al. used health professionals and Sacco et al. used undergraduate psychology students to deliver the intervention (Sacco, Malone, Morrison, Friedman, \& Wells, 2009 \& Williams et al., 2012). Graziano \& Gross utilized trained actors to deliver the intervention (Graziano \& Gross, 2009)

The type of telehealth intervention and the number of contacts with the participants also varied among the studies. Four studies utilized a short message service in which pre-recorded messages were sent to participants (Kim, 2007; Graziano \& Gross, 2009; Yoon \& Kim, 2008, \& Zolfaghari et al., 2011). Three studies provided participants with counseling and education two times a week during the first month and then once a week throughout the remaining two months (Aliha et al., 2013; McMahon et al., 2012; 
GLUCOSE PRIOR TO SURGERY

Nesari, Zakerimoghadam, Rajab, Bassampour \& Faghihzadeh, 2010). Another study the telephone intervention was completed once a week for the first three months and then every other week for the following three months (Sacco, Malone, Morrison, Friedman, \& Wells, 2009). One study utilized 30-minute telephone sessions with their coach for a total of fourteen coaching sessions (Wolever et al., 2010). While another study utilized a telephone intervention (diabetes medications adherence and lifestyle changes) in which participants received up to ten calls at four to six week intervals over twelve months, individualized to needs of participants (Walker et al., 2011). Another study utilized a 24minute long DVD followed by five telephone-coaching sessions, which totaled 2.5 additional hours of education by a nurse (Frosch, D., Uy, Ochoa, \& Mangione, 2011). Williams et al., utilized an automated interactive telephone system for six months (Williams et al., 2012). The automated system targeted key self-management behaviors specific to patients with diabetes. Feedback was specifically tailored to the participants and recommendations were provided (Williams et al.). Bell et al., utilized daily mobile phone based messages from nurse practitioners educating patients on self-care topics (Bell, Fonda, Walker, Schmidt, \& Vigersky, 2012). The variety of telephone messages could impact HgAlc levels because the telehealth interventions varied. The telehealth interventions ranged from pre-recorded messages to individualized responses but all involved contact with the patient.

There was a large study by Garg et al. that focused on decreasing fasting blood glucose levels the day of surgery. It was a two-phase study. The first phase, the education was provided by a physician during the preoperative visit. In the second phase, the education was provided by two nurse practitioners via face-to-face encounter or by a 
GLUCOSE PRIOR TO SURGERY

telephone follow-up call for those who were unable to be seen in the clinic (Garg et al., 2016). Two of the articles the intervention was done during the pre operative visit (Garg et al., 2016). Garg et al., found those in the intervention groups had a higher number of statistically significant percentages of patients who achieved target glucose levels the day of surgery compared to the control $(\mathrm{p}<0.05$ control vs. phase $1 \& p<0.001$ for control vs. phase 2) (Garg et al., 2016).

Based on these findings, there is strong evidence to show that the telehealth interventions reduced $\mathrm{HgAlc}$ levels in patients with Type 2 diabetes and decreased fasting blood glucose levels the day of surgery (Aliha et al. 2013; Bell, Fonda, Walker, Schmidt, \& Vigersky 2012; Garg, 2014; Gray, Drayton-Brooks, \& Williamson, 2013; Kim 2007; McMahon et al. 2012; Lee, Wyatt, Topliss, Walker, \& Stoney, 2014Nesari, Zakerimoghadam, Rajab, Bassampour \& Faghihzadeh, 2010; Walker et al. 2011;

Williams et al. 2012; Yoon \& Kim, 2008; Zolfaghari et al., 2011, Pare, Moqadem, Pineau, \& St-Hilaire, 2010). Although the evidence supports telehealth interventions, two RCTs and one quasi-experimental study did not find a significant difference between the telehealth intervention and the control group (Graziano \& Gross, 2009; Sacco, Malone, Morrison, Friedman, \& Wells, 2009; \& Wolever et al., 2010). All studies showed a decrease in $\mathrm{HgA} 1 \mathrm{c}$ levels in the intervention groups although results were not statistically significant. Small sample size and length of intervention may have had an impact on the results of these studies.

\section{Limitations}

It needs to be acknowledged that these studies did initially use convenience sampling, several had relatively small sample sizes, and they lacked the ability to blind 
GLUCOSE PRIOR TO SURGERY

researchers and participants because of the nature of the intervention. All of these limitations may have impacted the study findings though the actual process of randomizing to groups should have controlled for some of these design biases. In addition, one study used mail-in kits with filter paper cards to evaluate HgAlc (Walker et al., 2011), which do not have established validity or reliability when compared to the rigorous methods used in the remaining fourteen studies.

Other study weaknesses were also identified. One study had threats to internal validity with $95 \%$ of participants being male (McMahon et al., 2012). Other weaknesses of this study included possibility of self-selection, generalizability of the study, and questionable differences in lab measurements of HgA1c levels (McMahon et al.). Three articles found no significant difference between the intervention and control groups and each had limitations (Graziano \& Gross, 2009; Sacco, Malone, Morrison, Friedman, \& Wells, 2009 \& Wolever et al., 2010). Small sample size and participants with nonelevated HgAlc levels at baseline could have impacted the results (Wolever et al., 2010). Attrition bias may have also impacted one study because the intervention group started with thirty-one participants and was completed by only twenty-one participants (Sacco, Malone, Morrison, Friedman, \& Wells, 2009). Intensity of the program and the amount of time to complete intervention may be a reason for such high attrition (Sacco, Malone, Morrison, Friedman, \& Wells, 2009). Other limitations of this study were attrition bias, lack of blinding, and possible Hawthorne effect (Sacco, Malone, Morrison, Friedman, \& Wells, 2009). The study conducted by Graziano \& Gross had several limitations because of convenience sampling and differences in race (Graziano \& Gross, 2009). Difference in race category approached statistical significance (Graziano \& Gross). It was found that 
GLUCOSE PRIOR TO SURGERY

twice as many participants in the intervention group reported nonwhite race (Graziano \&

Gross). Since this was not statistically significant the results should not be impacted.

Aliha et al., found that participants were similar in all characteristics except for job status, length of disease, and fasting glucose levels which could have impacted results (Aliha et al., 2013). Other limitations included the research assistant not being blinded (Frosch, D., Uy, Ochoa, \& Mangione, 2011). In addition, the participants had considerable deficits in knowledge of diabetes and management of their disease based on a 23-item diabetes knowledge test developed by the University of Michigan (Frosch, D., Uy, Ochoa, \& Mangione, 2011).

As for the other studies that did not have statistical differences, there were several limitations. These limitations were attrition bias, small sample size, Hawthorne effect, and length of study, all of which could explain why the studies did not show statistically significant results.

\section{Literature review discussion}

The findings of this literature review and two prior systematic reviews (Gray, Drayton-Brooks, \& Williamson, 2013 \& Pare, Moqadem, Pineau, \& St-Hilaire, 2010) make it logical to infer that educational telephone interventions contribute to lower HgA1c levels in patients with uncontrolled diabetes. These findings are significant and consistent with the National Health Information Infrastructure (NHII) goals for promotion and utilization of telehealth systems (Bakken, 2006).

Underwood et al., found that patients with uncontrolled diabetes who were provided an intervention during the preoperative period had improved surgical outcomes (Underwood, Askari, Hurwitz, Chamarthi, \& Garg, 2014). There are gaps in the type and 
GLUCOSE PRIOR TO SURGERY

length of interventions required to improve glycemic control. This is especially true in regards to surgical patients. The type of interventions and length of interventions varied with each study. All studies that were conducted over 12 months had statistically significant results. It was also found that those done in shorter periods of time also had statistically significant results. Therefore, it still remains uncertain as to the length of time or contact with patients needed for improvement in glucose levels. Evidence has shown that even one follow-up telephone call with patients can decrease glucose levels the day of surgery (Garg et al., 2016). With the surgical population, time constraints are an important factor. Most patients require surgery and often the surgery will take place less than 30 days after the initial PAU visit. It is important to tailor the intervention to meet the needs of this specific population. Those interventions that involved patienttailored short message services with nurse recommendations for self-management seem to be most beneficial form of education. Nurse interaction seems to also play a role in the delivery of education. All of the studies that were conducted by a nurse or health educator had statistically significant results. A nurse or healthcare provider did not perform the education in the three studies, which did not show statistically significant results. When the intervention was delivered by para-professionals, no statistical difference was found (Sacco, Malone, Morrison, Friedman, \& Wells, 2009). In addition, another study showed no statistical differences in $\mathrm{HgAlc}$ levels when masters prepared social workers educated the patients (Wolever et al., 2010). In the systematic review conducted by Gray et al., it was concluded that in six out of ten studies in which telephone calls were made by nurses, the HgA1c levels were reduced (Gray, Drayton-Brooks, \& Williamson, 2013). Telephone follow-up calls are an effective way to reach patients in order to positively 
GLUCOSE PRIOR TO SURGERY

impact clinical outcomes (Gray, Drayton-Brooks, \& Williamson, 2013). Another study looked at the difference between a physician and nurse practitioner led intervention and found no difference between physician and nurse practitioner (Garg, 2016). Based on these findings, one could infer that nurse's involvement may play a crucial role in education and subsequent reduction in $\mathrm{HgAlc}$ levels. In addition, one study that was not planned to be a telephone follow-up had to resort to calling patients due to patients not being able to be seen in clinic (Garg, 2016). The intervention resulted in decreasing blood glucose levels the day of surgery and was one of the first studies looking at this population of interest (Garg, 2016). The findings of this study provided support for continuing to educate pre-operative patients with an APRN follow-up call. The results are promising APRN based interventions which can have a positive impact on glucose levels the day of surgery.

\section{Theoretical Framework}

The theoretical framework chosen to guide this Capstone project was John Kotter's 8-step change model. This 8-step approach was the guiding foundation for the implementation of an APRN telephone follow-up call for surgical patients with Type 2 diabetes and elevated HgAlc over 7\%. Kotter's change model involves eight specific steps leading to sustainable change (Kotter, 1996). Each of these steps are discussed in further detail and applied to the process of change later in the paper. 


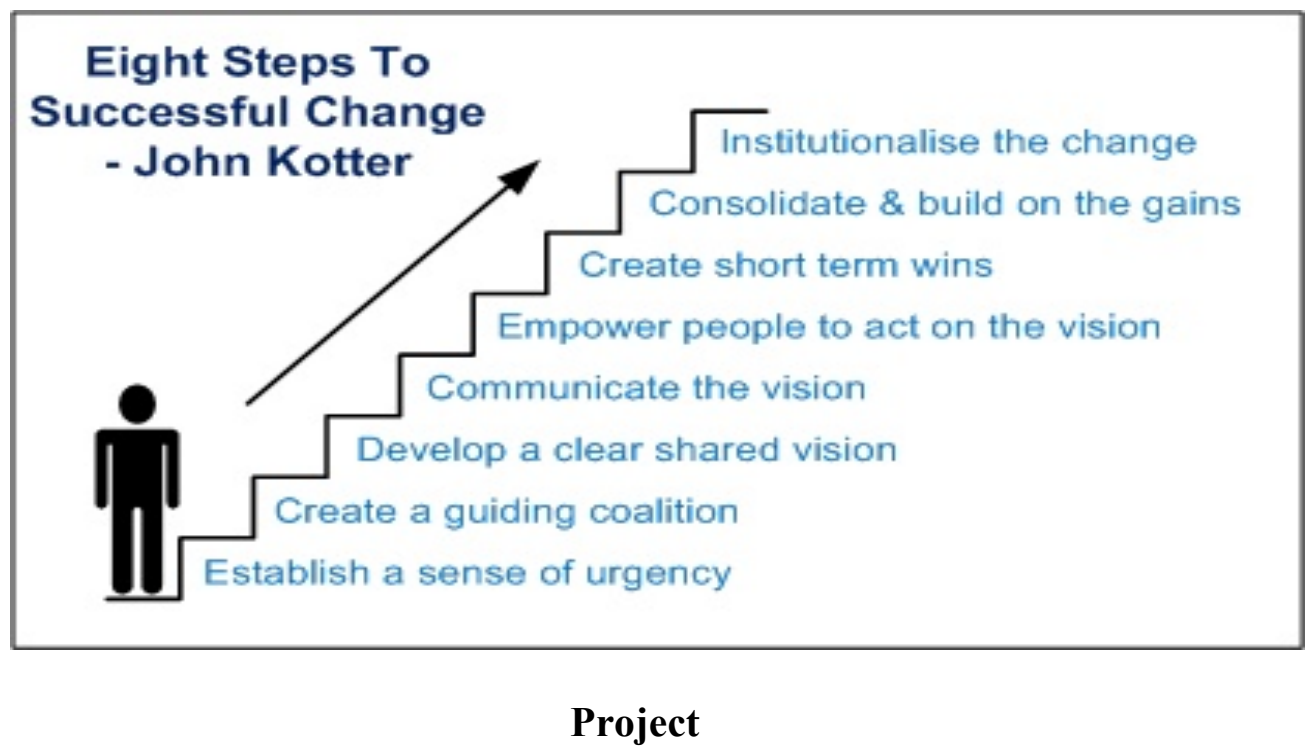

\section{Evidence-Based Project/Intervention Plan}

Health Resources and Services Administration (HRSA) defines telehealth as healthcare and education delivered via technology at a distance (Health Resources and Services Administration [HRSA], 2016). Telehealth can be used to help increase contact between patients and providers by reaching out to patients in their own homes thru telephone contact (HRSA, 2016). The potential for telehealth will continue to grow with an advanced way to reach and communicate with patients. Telehealth interventions via telephone follow-up have shown great potential in prevention and treatment of chronic disease such as Type 2 diabetes (HRSA, 2016).

The practice change was an APRN telephone follow-up call for patients with uncontrolled Type 2 diabetes and $\mathrm{HgA} 1 \mathrm{c}>7 \%$ undergoing a surgical intervention at a surgical center in North Central West Virginia. Patients with glucose levels over 155 $\mathrm{mg} / \mathrm{dL}$ were identified during the PAU visit and consented to either be in the control or intervention group if their $\mathrm{HgAlc}$ levels were over 7\%. A glucose level of $154 \mathrm{mg} / \mathrm{dL}$ is 
GLUCOSE PRIOR TO SURGERY

equal to a $\mathrm{HgAlc}$ level of $7 \%$, patients with a random glucose level of $155 \mathrm{mg} / \mathrm{dL}$ and over were identified as potentially having elevated $\mathrm{HgAlc}$ levels. A total of 50 participants were randomly assigned either to the control or the intervention group with 25 in each group. Demographics were collected on all participants. This included age, gender, ethnicity, surgical procedure, and body mass index. Hemoglobin A1c levels were collected for both groups, along with random glucose levels during the PAU visit and the day of surgery. The change process involved patients with a HgAlc over $7 \%$ receiving an APRN follow-up telephone call during the preoperative period. The telephone intervention provided education on the AADE7, which outlines seven self-care behaviors essential for self-management of diabetes during the preoperative period (American Association of Diabetes Educators, 2014). The AADE7 is an evidence based and patient centered framework of seven self-care behaviors that are essential for effective selfmanagement of diabetes (American Association of Diabetes Educators, 2014). These seven behaviors are eating healthy, being physically active, monitoring of glucose levels, adhering to medications, solving problems, coping in a healthy way, and reducing the risk associated with diabetes (American Association of Diabetes Educators, 2014). The preoperative telephone call also described the effect of hyperglycemia on surgical outcomes. The control group with a $\mathrm{HgAlc}>7 \%$ received usual care, which did not include any additional intervention unless the $\mathrm{HgAlc}$ was over $10 \%$. If the $\mathrm{HgAlc}$ was over $10 \%$, the surgeon was notified to determine if the patient would be permitted to proceed with the planned procedure. 
GLUCOSE PRIOR TO SURGERY

\section{Feasibility Analysis}

Determining feasibility is a key component in developing a practice change. The PAU was already a functioning unit with high quality care provided to patients and was the first in the nation to receive perioperative quality designation by the Association of perioperative Registered Nurses (AORN). The committed to OR Excellence (CORE) award recognizes perioperative nursing units that improve every aspect of perioperative patient care. The surgical center site of this project provided written support of the intervention and was a key component in the success of the intervention. The two lead RNs provided email support of willingness to consent patients identified by the APRNs as potential project participants. All APRNs gave verbal consent on willingness to support the proposed practice change in the PAU. The PAU serves around $45-50$ patients a day (Davis, 2016). Thirteen APRNs make up a full time equivalent of 6.9 (Davis, 2016). Historically, approximately twenty-five percent of the patient population in PAU have diabetes (Davis, 2016). The APRNs have on average around 30 minutes to spend with each patient obtaining past medical history, ordering appropriate testing, and providing interventions to optimize the patient for surgery. Follow-up telephone calls were made after labs results from $\mathrm{HgAlc}$ were reviewed. The lead nurse interventionist made the follow-up telephone calls and was not employed full time in the PAU. The role of the two lead RNs along with selected APRNs was to consent the participants for the pilot project on the day of the PAU visit. The telephone follow-up calls took less than ten minutes to complete. All needed resources included an already functioning PAU, patient population, willing participants, which were all in place and made initiation of this practice change feasible. 
GLUCOSE PRIOR TO SURGERY

\section{Resources}

According to Kotter, identification of key stakeholders is important during initiation of a new intervention (Kotter, 1996). Several stakeholders were impacted with the utilization of this intervention. From the organizational standpoint, this intervention impacted the surgeons, anesthesiologists, nurse anesthetists, APRNs, nurses, medical assistants, nurse managers, hospital administrators, surgical schedulers, secretary, and health care researchers. The organization was impacted by this practice change through incorporation of an evidence-based practice to improve surgical outcomes of patients with uncontrolled Type 2 diabetes. Surgical patients with uncontrolled diabetes were also impacted by this practice change. Patients selected for the intervention were provided with the opportunity to have additional education by the APRN interventionist prior to surgery. The goal was to decrease glucose levels the day of surgery for patients with uncontrolled Type 2 diabetes undergoing surgery.

Several resources were necessary for successful implementation of the follow-up telephone intervention. Many of the needed resources were already in place in the PAU. Lead nurses and APRNs needed communication and information about the planned practice change, which required an opportunity to educate staff. This education was done at staff meetings and during the morning before patients were seen in the clinic. Education included review of a script that the APRN interventionist making the preoperative call was to use when contacting patients. This script discussed the impact of uncontrolled diabetes on surgical outcomes. The script was developed, printed out, and distributed to the APRNs for review and reference. The intervention required some 
GLUCOSE PRIOR TO SURGERY

additional time from the APRN interventionist to make the follow-up calls. Several calls needed to be placed when the patient was unable to be reached during planned times.

Initiation of a new intervention can be costly and it is important to analyze the cost of starting up a new intervention. A benefit of this intervention was that aside from staff time for education, the short-term cost of supplies for the APRN script and the time spent completing the telephone follow-up call, there was not much additional cost for the unit. There was some cost associated with supplies to print out scripts (10 cents per copy). At WVUH PAU, the typically salary of an APRN was $\$ 50$ an hour and the typical salary for a registered nurse was $\$ 38$ (P. Fotta, personal communication, July 7, 2016). In the preadmission testing area, there were 13 APRNs, including the APRN interventionist, two lead nurses, and one clinical preceptor who required education about the intervention. Education of the APRNs and other staff took place during staff meetings and in the mornings prior to APRNs seeing patients. It was important to make sure all staff started out on the same level therefore, a baseline education session was provided. Once the intervention was initiated, it was important to look at the cost associated with the time spent by the APRN performing the intervention. This was tracked on a data collection sheet. Although some short-term costs were associated with the initiation of this project, the potential long-term cost of treatment for postoperative complications from hyperglycemia far outweighs the initial short-term investment (See Appendix A for Budget Plan and Justification Worksheet). 
GLUCOSE PRIOR TO SURGERY

\section{Needs assessment}

WVU Medicine (WVUH), the medical center for this project, has a single mission focused on improving the health of West Virginians through providing "excellence in patient care, research, and education" (WVU Healthcare, 2012). The goals and values of WVUH focus on eliminating health disparities among West Virginia citizens by expanding the delivery system, improving care and access to care, and fostering a culture of excellence (WVU Healthcare, 2012). WVUH strategic plan calls for "patient-centered system of care that emphasizes quality and effectiveness, and solves some of the persistent access problems faced by those seeking care at University-related sites" (WVU Healthcare, 2012). Initiation of an APRN telephone intervention fits with the mission of WVUH for patient centered and excellence in care. Providing patients with access to diabetes education via the telephone intervention provides a means of accessing and improving care. Evidence through research supports the use of telehealth services in improving HgA1c and glucose levels (Aliha et al. 2013; Bell, Fonda, Walker, Schmidt, \& Vigersky 2012; Frosch, D., Uy, Ochoa, \& Mangione, 2011; Garg, et al., 2014; Kim 2007; Lee, Wyatt, Topliss, Walker, \& Stoney, 2014; McMahon et al. 2012; Nesari, Zakerimoghadam, Rajab, Bassampour \& Faghihzadeh, 2010; Walker et al. 2011;

Williams et al. 2012; Yoon \& Kim, 2008; Zolfaghari et al., 2011). In addition, the use of telehealth services in order to decrease glucose levels and improve surgical outcomes is an example of excellence in care. Patient centered healthcare is critical and this intervention can have a positive impact on surgical patients with elevated $\mathrm{HgAlc}$ levels at WVUH. 
GLUCOSE PRIOR TO SURGERY

Analyzing the budget for a project is an important step in planning. The project required support from WVUH staff and manager. The APRN interventionist provided the majority of the services as part of the Capstone project, which was the most expensive part of the project. Other supplies such as computers, telephones, and other equipment were already established and available for use, and therefore, the organizational cost was minimal. Additional time required to make telephone follow-up calls and address obstacles was donated by the APRN interventionist.

It is important to have a strong coalition for the project. The members of the project team included the APRNs, unit secretary, lead RNs, and clinical preceptor. The lead nurse interventionist served the role of project manager and made the follow-up phone calls for patients that qualified for the intervention. The patients were educated based on a detailed evidence based script. This script was developed from the latest evidence in diabetes education from the American Association of Diabetes Educators. The APRNs were responsible for identifying patients and discussing the project to determine if patients are willing to participate. Select APRNs also helped to consent patients in addition to the lead RNs. Those patients who were willing to participate and had glucose levels $155 \mathrm{mg} / \mathrm{dL}$ or over while in PAU were consented by the lead RNs or APRNs. Once $\mathrm{HgA1c}$ levels were drawn and reviewed, patients with $\mathrm{HgA1c}$ levels $>7 \%$ were randomly assigned into one of two groups. The lead RNs and APRNs were helpful in providing project support and also obtaining consent from potential participants.

Content for the script will be updated on a yearly basis. This will be the role of the APRN interventionist and the clinical preceptor. In addition, the lead RNs and clinical preceptors were involved and were willing to help with maintaining sustainability 
GLUCOSE PRIOR TO SURGERY

of the intervention. It should take around four hours to review and update the script as needed each year based on new ADA and AADE guidelines and recommendations.

There are several functional requirements that must be addressed prior to initiation of a change project. Since PAU was already a fully functioning unit, no new equipment was required. Scripts were developed and distributed to the APRNs. In addition, meeting rooms were needed for education and other supplies such as paper and a printer were required to print out consents and educational materials. The unit secretary contacted the lead nurse interventionist when patients were consented. The APRN interventionist reviewed labs and determined if patients qualified for inclusion in the pilot project. Patients that were consented and met inclusion criteria were randomly assigned to the control or intervention group. Consents were secured in a locked box on the unit that was monitored by unit secretary and in a locked room. Confidentiality was maintained and HIPAA requirements were addressed with the signing of the consent.

It was also important to assess feasibility of creating a practice change. The ARPNs are skilled providers and with the additional education and guidance from APRN interventionist, the APRNs were able to properly educate and recruit participants for the pilot project. Resistance to change was a minor problem. The PAU had undergone a lot of changes and some staff were overwhelmed with more change. This resistance was addressed using Kotter's change model to guide the practice change. One benefit was that the APRN interventionist was employed in the PAU for over ten years and was viewed as a leader in the PAU. This helped to decrease resistance, establish a sense of urgency, and gain buy-in from the majority of the staff. 
GLUCOSE PRIOR TO SURGERY

Another potential issue of concern would be the demands on resources to develop the practice change. The APRN interventionist did the majority of the work, and this did not add any additional cost to the organization since this was part of the DNP Capstone requirement. With the small number of patients required for this pilot project, it did not impact the workflow or add any additional demands on the resources in PAU aside from identification of patients and obtaining consent. Education of staff was done between caring for patients and before the start of the day. This did not impact the workflow because the APRNs had time in between patient visits to follow-up on patient issues such as elevated $\mathrm{HgA} 1 \mathrm{c}$ levels.

Another issue that was of concern was space for making the follow-up telephone calls. The PAU was under construction and the unit was sharing space with other providers. This issue was addressed by having a designated provider area where calls were made and calls were also made in APRN interventionist's private office.

The long-term plan for this project would be for patients with Type 2 diabetes and HgA1c levels greater than $7 \%$ to have a follow-up telephone call from the APRNs. The goal was for this to be part of usual care in the PAU, and for this intervention to be written as a policy at WVUH. Development of the intervention into a policy would help to create sustainability of the intervention.

Development of a SWOT analysis can be a useful planning tool to assess for any internal and external influences that could impact the changes process (Taylor, 2016). The "S" stands for strengths, "W" for weaknesses, "O" for opportunities, and "T" for threats (Taylor, 2016). A strength of this practice change was that currently patients with diabetes had HgA1c levels and glucose levels drawn while in PAU. Therefore, the labs 
GLUCOSE PRIOR TO SURGERY

needed to identify patients with uncontrolled diabetes are currently being completed as part of the routine PAU visit. In addition, the intervention provided an opportunity to improve surgical outcomes and the care of surgical patients with hyperglycemia. The literature was supportive of using a telephone intervention to decrease $\mathrm{HgAlc}$ and glucose levels to provide diabetes education for patients. The delivery of this telephone intervention also provided an opportunity to improve surgical outcomes, patient safety, and patient satisfaction. This intervention also provided additional diabetes education for those patients with uncontrolled Type 2 diabetes. Often, when patients are in PAU, they have seen the surgeon prior to their visit and are often overwhelmed with the abundance of information they are receiving. The follow-up APRN call increased communication with patients in their own environment and allowed them to ask questions they may have forgotten. This gave the patients a better opportunity to ask questions, and discuss all of the information received during the PAU visit while the APRN reinforced diabetes education and self-management. In addition, data from this project was collected and analyzed, providing an opportunity for other outcomes to be measured in the future. A final strength is that evidence-based practice change of an APRN telephone follow-up call to deliver education and management tips to preoperative patients with uncontrolled diabetes supports the mission, values, goals, and strategic plan of WVUH.

Some weaknesses identified for this project include loss of staff productivity in the PAU during training sessions, although this was minimized by targeting periods of downtime to provide the training. Also, there was a limited amount of staff so this placed some minor strain on an already overworked staff. Another weakness was the time investment related to being unable to reach patients over the phone. Some participants 
GLUCOSE PRIOR TO SURGERY

needed to be called multiple times before they were reached. In addition, a potential weakness was that some elderly patients could have been affected by difficulty hearing over the phone. This issue was not found to be a problem and would have been addressed by sending a written letter with the information and education from the script to those participants who were unable to be reached or had difficulty hearing over the telephone. This letter would contain all of the information that the APRN discussed with the patient over the telephone.

There were also some potential threats that were identified with the implication of this APRN telephone intervention. The first was that the change could create resentment from an overworked staff. This was addressed utilizing Kotter's change model to guide the practice change. Staff were involved with the process of change and buy-in was obtained from all members of the coalition. Other potential threats could be issues with lab values and reporting of labs, but this was not found to be an issue.

\section{Evidence of Support}

WVUH is a Magnet hospital that values the use of evidence based practice and excellence in nursing. The manager of PAU was very supportive with moving forward with the implementation of this intervention, and provided a letter of support for the initiation of the APRN follow-up telephone call for patients with uncontrolled diabetes undergoing a surgical intervention (Appendix B). Staff in the PAU were excited to be a part of the practice change and voiced willingness to make project a success. 
GLUCOSE PRIOR TO SURGERY

\section{Timeline of Project}

The timeframe for completion of the project was outlined in a SMART Work plan. The intervention took place October 2016 through January 2017. See attached SMART work plan for the detailed plan (Appendix C).

\section{Measureable Project Objectives}

There were two overall goals for this capstone project. The first goal was to improve patient education and management of patients with Type 2 diabetes and elevated HgA1c undergoing surgical intervention at an Academic Surgical Center in North Central WV via a validated change process. This goal was obtained via two aims. The first aim was to develop and evaluate a practice change management plan utilizing Kotter's 8-step change management process. Measurement of the change process was done via meeting SMART plan objectives. The second aim was to determine feasibility of the practice change. Measurement of this aim was done via assessment of feasibility of time to make the follow-up APRN call.

The second goal was to decrease fasting blood glucose levels the day of surgery. This goal was operationalized through two aims. The first aim was to develop an evidence based script for education via telephone follow-up call from APRNs. Patients with Type 2 diabetes and elevated HgA1c levels over 7\% received additional telephone education based on the American Association of Diabetes Educators 7 self-care behaviors for self-management of diabetes. This approach was a change in the current practice, which involved no additional education or notification for patients with hyperglycemia during the preoperative period unless their HgA1c was greater than $10 \%$. If the $\mathrm{HgAl} \mathrm{c}$ was greater than $10 \%$, the surgeon was notified and determined if the 
GLUCOSE PRIOR TO SURGERY

patient could proceed with the planned surgery. The second aim was to evaluate a

delivery model that included education via telephone follow-up call from an

APRN. Patients with Type 2 diabetes and HgAlc levels over 7\% were identified, and glucose levels were compared between the PAU visit and the day of surgery.

\section{Measurement Tools}

SMART objectives served as the work plan and guideline for the change process and initiation of intervention. These objectives were communicated and revised as needed throughout the project. The SMART objectives served as a timeline and framework for the project.

Guidelines from the American Association of Diabetes Educators (AADE) were utilized for evidence-based self-management behaviors that were provided to patients via the telephone follow-up call by the lead nurse interventionist. Random blood glucose levels and HgA1c were analyzed during the PAU visit. In addition, patients had fasting blood glucose levels done the day of surgery, which was the current standard of care. These values were analyzed and compared to the day of surgery fasting glucose levels to determine if there was a decrease in fasting blood glucose levels the day of surgery.

\section{Evaluation Plan}

GOAL 1: To improve patient education and management of patients with Type 2 diabetes and elevated HGA1c undergoing surgical intervention at Academic Medical Center in North Central WV via a validated change process. 
GLUCOSE PRIOR TO SURGERY

AIM 1a: Develop and evaluate practice change management plan utilizing Kotter's 8step change management process.

\section{GOAL 1, AIM 1 EVALUATION PLAN}

To develop a SMART work plan in which measurable objectives serve as timeline for development of practice change in implementing a follow-up APRN telephone call for patients with Type 2 diabetes and $\mathrm{HgAlc}$ levels $<7 \%$ (Appendix C). The SMART work plan served as a timeline for meeting objectives during the practice change utilizing Kotter's 8-steps. Each objective was measurable and time was allotted in order for the APRN interventionist to have enough time to reasonably complete each objective. This SMART work plan served a as guide and was communicated with the nurse manager in PAU, with update and changes based on changes that occur during the project. The following lists the steps that were planned for this project.

a) Apply for IRB approval for an APRN telephone follow-up call for patients with Type 2 diabetes and HgA1c levels over 7\%.

b) Secure meeting room, time, and date to present intervention to key stakeholders, champions, and assemble coalition.

c) Meet with key stakeholders and champions to present intervention along with evidence to support intervention and establishing a sense of urgency for needed change.

d) Development of handouts and guidelines regarding practice change and information assembled together with evidence for practice change utilizing Kotter's change model and present clear vision for change. 
e) Send email notification of locations, dates, and times to discussion role in implementation of the intervention to lead RNs, clinical preceptor, and APRNs.

f) Education and training on the intervention completed with APRNs and lead RNs. Handouts and scripts to be administered to staff was intended to help empower staff to be a part of the change process.

g) APRNs in PAU will start utilizing telephone intervention on patients randomized into the intervention group with Type 2 diabetes and $\mathrm{HgA} 1 \mathrm{c}$ levels over $7 \%$.

h) Follow-up with staff to address any issues with intervention, resolve obstacles, and celebrate small wins.

i) Evaluation of intervention to be assessed by looking at fasting glucose levels the day of surgery for those patients that received the intervention and those that were the control.

j) Complete data analysis and assessment of Kotter's practice change in PAU.

k) Intervention written as a protocol and part of usual care for patients with Type 2 diabetes and elevated $\mathrm{HgA} 1 \mathrm{c}$ levels undergoing a surgical intervention.

\section{GOAL 1, AIM 2 EVALUATION PLAN:}

1) To determine the amount of time spent by APRNs making telephone follow-up call. This time was to be tracked in minutes and to be assessed to determine if the time allotment will be feasible to implement in the clinic. The average amount of time was be determined and reported as the average time required for making calls. This will be presented to management for evaluation of feasibility of practice change. 
GLUCOSE PRIOR TO SURGERY

2) Identification of challenges or obstacles that arise during the change process. Meeting the objectives of the SMART work plan will serve as an evaluation of the change process.

GOAL 2: To decrease fasting blood glucose levels the day of surgery.

GOAL 2 AIM 1a: To develop a delivery model that includes education via telephone follow-up call from APRNs. Patients with Type 2 diabetes and elevated HgA1c levels over $7 \%$ in the intervention group will get additional telephone education that focuses on improvement of self-management and identification of potential negative surgical outcomes associated with hyperglycemia. This approach will be a change in the current practice, which involves no additional education or notification for these patients with hyperglycemia during the preoperative period.

1) Development of script for APRN telephone follow-up call via American Diabetes Association (ADA) guidelines. These guidelines will be used for education of patients along with information regarding the increase risk of poor surgical outcomes related to hyperglycemia.

GOAL 2 AIM 2b: To evaluate a delivery model that includes education via telephone follow-up call from APRNs. Patients with Type 2 diabetes and HgAlc levels over 7\% will be identified and glucose levels will be compared to glucose levels during PAU visit and day of surgery. 
1) To evaluate glucose levels during visit in PAU and then compare those levels the day of surgery for both the control and the intervention group utilizing One-way ANOVA.

\section{Sample}

\section{Results}

The pilot project contained a convenience sample of 50 participants. The inclusion criteria were adult patients over the age of 18; Type 2 diabetes, random glucose level of $155 \mathrm{mg} / \mathrm{dL}$ or greater during PAU visit, willing to participate in pilot project and sign consent, and English speaking participants with telephone access. Participants were excluded if they did not have Type 2 diabetes, were under the age of 18 years old, unable to speak English, and $\mathrm{HgAl} \mathrm{c}$ was less than $7 \%$, or refused to consent to being part of the pilot project.

A total of 50 participants were part of the pilot project, with 25 in the control group and 25 in the intervention group. Participants were selected by randomly drawing from an envelope to determine if the participant would receive the intervention or be part of the control group. The envelope contained 25 tags for the intervention and 25 tags for the control. Fifty six percent of participants were female and $44 \%$ were male. All 50 participants were white. Sixty percent of the participants were married, while $10 \%$ were divorced and $2 \%$ separated. Fourteen percent of participants were single, $12 \%$ widowed, and $2 \%$ had a significant other (Table 1 ).

The mean pre glucose levels for both the intervention and control were 248.52 $\mathrm{mg} / \mathrm{dL}$ ( $\mathrm{n}=50, \mathrm{SD}=68.164)$. While the mean post glucose levels for both groups was 
$169.74 \mathrm{mg} / \mathrm{dL}(\mathrm{n}=46, \mathrm{SD}=56.648)$. The average $\mathrm{HgAl}$ c for both groups was $9.18 \%$ $(\mathrm{n}=50, \mathrm{SD}=1.62816)$. Participant's ages range from $29-79$ years, with the mean age being 53.6 years old ( $\mathrm{n}=50, \mathrm{SD}=10.836$ ). BMI of participants ranged from 24 to 74 , with the mean BMI of $37.06(n=50, \mathrm{SD}=8.497)$. (Table 2).

One-way ANOVA was utilized to compare impact of telephone education on post glucose levels between the control and intervention group. Levene test was assessed to determine homogeneity of groups with significance $p=0.667$. The analysis of variance showed that the effect of telephone education on post glucose levels was not significant $\mathrm{F}(1,44)=.048, \mathrm{p}=.827$. There was no significant difference statistically between the control and intervention on pre glucose levels with $\mathrm{F}(1,48)=.187, \mathrm{p}=0.668$, HgA1c $\mathrm{F}(1,48)=.241, \mathrm{p}=0.625$, age $\mathrm{F}(1,48)=.242, \mathrm{p}=0.625$, and BMI $\mathrm{F}(1,48)=.299, \mathrm{p}=0.587$ (Table 3). There was a reduction in pre and post glucose levels for both groups. The control groups average random glucose level before surgery was $244.32 \mathrm{mg} / \mathrm{dL}(\mathrm{n}=25$, $\mathrm{SD}=69.564)$ and was reduced to $171.44 \mathrm{mg} / \mathrm{dL}(\mathrm{n}=25, \mathrm{SD}=54.928)$. The intervention groups average random glucose before surgery was $252.7 \mathrm{mg} / \mathrm{dL}(\mathrm{n}=25, \mathrm{SD}=67.900)$ and was reduced to $167.71 \mathrm{mg} / \mathrm{dL}(\mathrm{n}=21, \mathrm{SD}=59.931)$ the day of surgery (Table 4$)$.

\section{Evaluation of Goals}

GOAL 1: To improve patient education and management of patients with Type 2 diabetes and elevated $\mathrm{HgAl} \mathrm{c}$ undergoing surgical intervention at Academic Medical Center in North Central WV via a validated change process. 
GLUCOSE PRIOR TO SURGERY

AIM 1a: Develop and evaluate practice change management plan utilizing Kotter's 8step change management process.

GOAL 1, AIM 1 Evaluation Plan/Results

Development of SMART work plan with measurable objectives served as the timeline for development of practice change in implementing a follow-up APRN telephone call for patients with Type 2 diabetes and $\mathrm{HgAlc}$ levels $>7 \%$ (Appendix C). The SMART work plan served as the timeline for meeting objectives during the practice change utilizing Kotter's 8-steps. Each objective was measurable and time was allotted in order for the APRN interventionist to have enough time to reasonably complete each objective. The SMART work plan served as a guide and was communicated with the nurse manager in PAU and was updated and changed based on changes that occur during the project. The following lists the steps planned for the project along with the results.

1) Apply for IRB approval for an APRN telephone follow-up call for patients with Type 2 diabetes and $\mathrm{HgA} 1 \mathrm{c}$ levels over 7\%

a. Step one accomplished. Institutional Review Board approval obtained and shared with WVU Medicine Research Council. Approval was also given via WVU Medicine Research prior to staring the pilot project.

2) Secure meeting room, time, and date to present intervention to key stakeholders, champions, and assemble coalition

b. Step two accomplished. Emails were sent to key stakeholders including upper management and PAU staff along with information regarding pilot project. 
3) Meet with key stakeholders and champions to present intervention along with evidence to support intervention and establishing a sense of urgency for needed change.

c. Step three accomplished. Met with Paula Fotta nurse manager and presented evidence for need for change in practice in PAU and explained purpose of pilot project. Provided supporting literature of use of telephone intervention to providing patient education.

4) Development of script and guidelines regarding practice change and information will be put together with evidence for practice change utilizing Kotter's change model and present clear vision for change

d. Step four accomplished. Script was developed and sent for committee approval (Appendix D). Guidelines were developed and evidence gathered to present to staff of PAU.

5) Send email notification of locations, dates, and times to discussion role in implementation of the intervention to lead RNs, clinical preceptor, and APRNs.

e. Step five accomplished. Emailed PAU staff information regarding pilot project and role in project.

6) Education and training on the intervention completed with APRNs and lead RNs. Handouts and scripts will be administered to staff along with empowering staff to be a part of the change process. 
GLUCOSE PRIOR TO SURGERY

f. Step six accomplished. Met with medical assistants and APRNs and personally discussed the pilot project and role in the project. Emailed and printed copies of research supporting telephone intervention.

7) APRNs in the PAU will start utilizing telephone intervention on patients randomized into the intervention group with Type 2 diabetes and $\mathrm{HgAlc}$ levels over $7 \%$.

g. Step seven accomplished. APRNs started to recruit participants on October 17, 2016 and willing participants were consented.

8) Follow-up with staff to address any issues with intervention, resolve obstacles and celebrate small wins

k. Step eight accomplished. Weekly emails were sent to staff regarding number of participants and any issues were addressed on a weekly basis.

9) Evaluation of intervention will be assessed by evaluating fasting glucose levels the day of surgery for those patients who received the intervention and those who were randomized to the control

1. Step nine accomplished. One-way ANOVA found that there was no statistical significance between the control and intervention groups $\mathrm{p}=0.827$.

10) Complete data analysis and assessment of Kotter's practice change in PAU

m. Step ten accomplished. Complete data analysis in results section.

11) Intervention will be written as a protocol and will become a part of usual care for patients with Type 2 diabetes and elevated HgAlc levels undergoing a surgical intervention 
n. Step eleven not accomplished. Further suggestions for PAU based on findings are discussed in the discussion section.

GOAL 1, AIM 2 Results

1) To determine the amount of time spent by APRN making telephone follow-up call. This time was tracked in minutes and was assessed to determine if the time allotment would be feasible to implement in the clinic setting. The average amount of time was determined and reported as the average time required for making calls.

* The average amount of time required to make calls was $91 / 2$ minutes.

2) Identification of challenges or obstacles that arose during the change process. Meeting the objectives of the SMART work plan served as an evaluation of the change process.

* Very few obstacles arose during the change process. The first issue that was encountered was the need to obtain approval from the WVU Medicine research council, which was an unexpected step that was not known to exist to the interventionist until the project was being launched. Approval had been obtained from the unit manager but not WVU Medicine research council. Once the need to have approval was identified, all required information needed was presented to the research council. The approval was obtained from WVU Medicine and therefore no delay occurred in the SMART objectives. All members in the PAU were on board and educated prior to the start of the pilot project. Staff members 
were excited about participating in the project and were willing to help discuss the project with patients and recruit participants. The only issue was some resistance from one APRN regarding her role in education and recruitment of patients. She was not discussing the pilot project with the patients and was just telling the lead $\mathrm{RN}$ to go in and discuss the project and determine if patient wanted to participate. I met with the APRN and clarified her role in the pilot project and we did not have any further issues. All SMART objective were met without difficulty and some objectives were achieved before the planned date.

GOAL 2: To decrease fasting blood glucose levels the day of surgery.

GOAL 2 AIM 1a: To develop a delivery model that included education via telephone follow-up call from APRN. Patients with Type 2 diabetes and elevated HgA1c levels over $7 \%$ in the intervention group received additional telephone education that focused on improvement of self-management and identification of potential negative surgical outcomes associated with hyperglycemia. This approach was a change in the current practice, which involved no additional education or notification for these patients with hyperglycemia during the preoperative period.

1) Development of the script for APRN telephone follow-up call was based on the American Association of Diabetes Educators AADE 7 Self Care Behaviors. This framework was used for education of patients. In addition, patients were provided 
GLUCOSE PRIOR TO SURGERY

with information regarding the increase risk of poor surgical outcomes related to hyperglycemia.

*APRN script developed based on Diabetes Educators AADE7 Self Care Behaviors and was used by the APRN interventionist to make telephone calls (Appendix D). Patients were also educated on the risk of hyperglycemia during the surgical period. Patients were given opportunities to ask questions and referred to resources that could help them achieve glycemic control.

GOAL 2 AIM 2b: To evaluate a delivery model that includes education via telephone follow-up call from APRNs. Patients with Type 2 diabetes and HgAlc levels over 7\% were identified and glucose levels were compared to glucose levels during the PAU visit and the day of surgery.

1) To evaluate glucose levels during the visit in the PAU and then compare those levels the day of surgery for both the control and the intervention group utilizing one-way ANOVA.

* There was no significant difference statistically between the control and intervention on pre glucose levels with $\mathrm{p}=0.668$, post glucose levels $\mathrm{p}=0.827$, HgAlc $p=0.625$, age $p=0.625$, and BMI $p=0.587$ (Table 3$)$. There was a reduction in pre and post glucose levels for both groups. The control groups average random glucose level before surgery was $244.32 \mathrm{mg} / \mathrm{dL}$ and was reduced to $171.44 \mathrm{mg} / \mathrm{dL}$. The intervention groups average random glucose before 
GLUCOSE PRIOR TO SURGERY

surgery was $252.7 \mathrm{mg} / \mathrm{dL}$ and was reduced to $167.71 \mathrm{mg} / \mathrm{dL}$ the day of surgery (Table 4).

The overall goal of this intervention was for patients to have a decrease in fasting glucose levels the day of surgery. Patients with normal glucose levels have better outcomes over those with hyperglycemia. This decrease in glucose levels could also impact the rate of post-operative infections. In addition, this intervention enhances practice to decrease unplanned cancellations the day of surgery due to severe hyperglycemia, helps patients become better optimized, improves patient safety, and decreases other surgical complications related to hyperglycemia.

For this project, success was planned to be a reduction in the glucose levels the day of surgery compared to the glucose levels obtained in the PAU. Patients with elevated glucose levels during surgery are at risk of experiencing post-operative complications such as infections, increased length of hospital stay postoperatively, increased ICU admissions, increased risk for myocardial infarctions, stroke, and an increased mortality due to hyperglycemia (Loh-Trivedi, 2011).

\section{Discussion and Recommendations}

John Kotter's 8-step change model provided the theoretical framework for initiation of the pilot project. This framework was used as a guide and provide evidence for support during the pilot project. Each of the 8 steps will be further discussed along with the application of the theoretical framework during the pilot project.

The first step was to work within the organization to develop a sense of why it was urgent for stakeholders to consider making the change (Kotter, 1996). According to Kotter's findings, this is a crucial step in the change process because many organizations 
fail in implementing change due to lack of motivation by individuals to participate in the change (Kotter, 1996). During this step, members of the group must be convinced that the current situation is unacceptable (Kotter, 1996). Failure to create a sense of urgency may results in employees feeling overwhelmed and returning to the status quo (Kotter, 1996). In the PAU, the need for change of the current management of patients with uncontrolled diabetes due to the risk of poor surgical outcomes associated with hyperglycemia was discussed with the APRNs. APRNs were provided with evidence to support the need for change and were supportive of the change. The healthcare system at WVU Medicine was in a period of transition and the APRNs in the PAU were under a high level of scrutiny. This scrutiny was used as leverage to create a sense of urgency to make the proposed changes. APRNs were given evidence that supported a follow-up APRN telephone call for patients with elevated $\mathrm{HgA1c}$ levels as an effective intervention to improve glucose levels the day of surgery. Improvement of post operative outcomes can demonstrate the value of the APRNs in being able to provide evidence based care by recognizing a practice and working to make a positive change via cost, time efficiency, and improved outcomes. Patients with diabetes have been found to have poorer outcomes over those who do not have diabetes (Plodkowki \& Edelman, 2001). Advance practice registered nurses can make a difference in patient outcomes but need to act now. Obtaining buy-in during this step was critical to the long-term sustainability of making the change (Kotter, 1996). Buy-in was obtained prior to initiation of pilot 
project and participants were excited to be a part of the pilot project.

The second step of Kotter's change model was to develop a coalition or team to guide the change (Kotter, 1996). The key component of this step was to establish a powerful team that will be able to help support a collaborative change (Kotter, 1996). The coalition should be built upon a strong group of members with a strong leader to guide the team (Kotter, 1996). Every member of the team was a valuable and respected member. In PAU, the coalition comprised of the APRNs involved with the practice change, along with the lead RNs, medical assistants, nurse manager, director of PAU, clinical preceptor, and unit secretary. Each member brought value and expertise to the project during the process of change. This role required strong leadership direction and the ability to help the coalition see the vision and need for change (Kotter, 1996). The coalition was built of the APRNs, the lead RNs, and clinical preceptor, all who are currently a vital part of the success of PAU. The APRNs in PAU provide high quality care for the patients undergoing surgery. Leadership was demonstrated by respecting members of the coalition and showing appreciation for each member's role in the change process. Weekly email reminders and encouragement was provided by the APRN interventionist. The staff was kept up to date on the project and number of participants recruited. Efforts of the staff were identified and members of the team were encouraged and praised for their role. The excitement of the staff grew as more participants were recruited for the pilot project. The positive working relationship with 
the staff created an environment of trust and desire to be a part of this process and success of the pilot project.

Kotter's third step in the change process was to create a vision (Kotter, 1996). This third step involved development of a clear and concise plan that guides the organization and provides direction for achieving the vision (Kotter, 1996). It was important for the vision to be clear to all members of the coalition. A clear vision will help to provide clarity and members will be more willing to accept the vision and make the necessary change (Kotter, 1996). Providing clarity of the vision helps members of the team to see and understand the vision and then be more willing to accept the vision (Kotter, 1996). Prior to the project all members of the coalition were provided with the vision and strategy for achieving the change in practice. The vision for the project was to improve blood glucose outcomes by APRN reaching out to 25 poorly controlled Type 2 diabetic patients undergoing a surgical intervention at WVUH. An APRN follow-up telephone call was made to provide additional education and guidance on selfmanagement of diabetes. Another 25 patients were randomly assigned into the control group. The intervention group received a follow-up telephone call in which the lead nurse interventionist provided education to all participants. The script was developed utilizing the latest evidence for the standards of practice in diabetes education. The goal was to improved blood sugar control in the pre-operative period as a result of the additional education and knowledge gained by the patients during the follow-up call. 
The fourth step in Kotter's change model was to communicate the vision (Kotter, 1996). According to Kotter, members of the group will want to follow the vision if they see the leader leading by example (Kotter, 1996). It will be important for members to be able to openly communicate concerns and opinions regarding the vision and their role in creating the vision (Kotter, 1996). The vision was communicated to the members of the coalition during informal meetings with each member of the group. Members of the coalition were provided written education via email in addition to meeting with each member individually. The APRN interventionist acted as a role model for this change by demonstrating how to recruit and consent participants. The APRN interventionist was actively involved and had an open line of communication so that members could express concerns regarding the vision. Members of the coalition were able to contact the lead nurse interventionist when any questions arose. The APRN interventionist played an active role and led by example.

The fifth step in Kotter's change model was empowering others to be active in creating the vision. This step involved working to remove any obstacles or barriers while empowering members to make a change (Kotter, 1996). Removing barriers can empower others to execute the vision and help to move forward with the change (Kotter, 1996). The role of the APRN interventionist was to quickly identify any obstacles or barriers and empower the members to move towards the vision. This was done by recognizing members when they worked towards making the change and also rewarding 
their behavior with positive reinforcement. One member was struggling with education of participants regarding the project. This was addressed with this member and clarification was provided. After meeting with the member no further issues arose. The members of the coalition felt empowered and wanted to make a difference in the lives of patients with uncontrolled diabetes. The members were excited when they successfully recruited participants and were happy to help and participate.

The sixth step in Kotter's change model was to focus on creating short term wins (Kotter, 1996). This step focuses on developing performance goals and rewarding members when they have achieved these goals (Kotter, 1996). A celebration was held on the first and final day of the project. This helped to make the staff feel good about their role and the role they had in leading the change. Each staff member received verbal and written acknowledgement on a weekly basis. Each week was a celebration of the number of participants recruited the following week. This helped to build excitement within the group. These recognitions helped staff track progress and celebrate short-term wins along the way.

The seventh step in Kotter's change model was consolidation of improvements and working to produce more change (Kotter, 1996). This seventh step involved working to identify small wins and pushing to keep the vision alive even when obstacles arose (Kotter, 1996). The change process was a learning experience, which takes time, therefore it was important to not declare victory too soon (Kotter, 1996). It was 
GLUCOSE PRIOR TO SURGERY

important to celebrate the small victories but also continue to focus on the long-term vision for success (Kotter, 1996). The role of the APRN interventionist was to set goals, act as a leader/mentor, and celebrate small wins along the way. Each week the APRN interventionist identified things that were working and those that were not working. Things that were not working were identified and immediately addressed. Momentum of the pilot project was continued by involving the staff by updating them with weekly progress announcements. This kept all members of the coalition involved and excited.

The final step in Kotter's change model was institutionalizing new approaches (Kotter, 1996). During this final step it was important to ensure that the changes had become integral to the organization's culture (Kotter, 1996). Support of leaders and members continued to be an important step in sustaining the change (Kotter, 1996). Any new members needed to be informed and share in the vision for change (Kotter, 1996). The role of the APRN interventionist was to make the change last and integrate it into the culture of the PAU. The goal of the pilot project was to determine if an APRN telephone intervention was an effective way to educate patients with uncontrolled glucose prior to surgery. Integration of this intervention into the usual standard of care protocol will serve as the sustainability of the project. Having the lead RN and clinical preceptor in place to continue the success of the change is important for succession. Feasibility of the pilot project will be discussed with nurse manager to determine if follow-up APRN telephone call may be part of the standard of care in PAU. 
GLUCOSE PRIOR TO SURGERY

After completion of this pilot project there are several recommendations and suggestions that can be made for the site. The first recommendation would be to use Kotter's theoretical framework to guide future changes in practice. The staff felt involved in the change process and were willing to make changes. Past changes were not made utilizing this theoretical framework, and those have failed and not been sustained. The successfulness and ease of utilizing Kotter's 8-step process will prove to be beneficial with future changes.

The literature was supportive of a telephone follow-up call in order to decrease glucose levels. Based on the literature review and pilot project patients should be notified if their $\mathrm{HgA} 1 \mathrm{c}$ levels are over 7\%. Those patient's whose HgAlc levels are over 9\% would benefit from the follow-up APRN call and additional education. The mean average of $\mathrm{HgAl}$ c for both groups was $9.1 \%$ and these patients were able to make greater improvements in their glucose levels with the additional education. The additional education along with referrals to outside educational resources and primary care providers can help to decrease fasting glucose levels and improve surgical outcomes. Based on the findings it is recommended that the site continue with APRN telephone follow-up call for patients with $\mathrm{HgAlc}$ levels over 9\%. Those patients with HgAlc levels between $7-8 \%$ will still receive a call notifying them of their elevated $\mathrm{HgAlc}$ levels but will not receive any additional education.

Based on the finding of this pilot project it would be feasible to apply this project to other settings. This project would fit well when patients are first identified as surgical candidates. Their HgAlc levels could be assessed and if elevated patients could be contacted by the nurse and instructed on ways to improve glucose along with providing 
GLUCOSE PRIOR TO SURGERY

resources and referrals back to PCP. This could be a stopping point and patients would have elective surgeries delayed if they did not show improvement in glucose levels. Having the surgeons identify the patients would allow for more time for change during the preoperative period. Once patients are seen at the PAU there is often not a lot of time before their surgical procedure. If the intervention was done earlier, it could prove to be more beneficial for the patients.

Additionally, if the pilot project were to be repeated some changes would be recommended. The glucose levels during the PAU visit were random and patients were not fasting. Results may have been different if comparing non-fasting glucose levels during preoperative visit to non-fasting glucose levels the day of surgery. In addition, it would be beneficial to look at surgical outcomes of the patients. Future outcomes that could be measured would be length of stay, number of postoperative infections, number of ICU admissions, and number of MIs, strokes, and deaths during the postoperative period.

As with any future recommendations it is important to evaluate the process of the project and identify any unintended outcomes. Fifty participants were recruited for the pilot project. All 25 participants in the control group had their planned surgery. Only 21 participants in the intervention group had their planned surgery. There was homogeneity between both groups and both groups were recruited for the project and signed the consent. Although the results of the pilot project did not show a statistically significant difference between the groups, the result may provide for some clinical evidence to guide practice. Four out of the 25 participants in the intervention decided to postpone surgery after receiving the intervention. Clinically this was of significance, because the 
GLUCOSE PRIOR TO SURGERY

additional education and knowledge may have provided them with insight into the need to delay the surgery until better glycemic control was obtained. Although this was not measurable it does provide support of the APRN follow-up telephone intervention. The participants in the control group knew they were in the pilot project and they did not receive the education and still proceeded with their planned surgery. The mean pre glucose for the control group was $244 \mathrm{mg} / \mathrm{dL}$ and the post glucose was $171 \mathrm{mg} / \mathrm{dL}$. While the mean pre glucose for the intervention group was $252 \mathrm{mg} / \mathrm{dL}$ and the post glucose was $167 \mathrm{mg} / \mathrm{dL}$. Clinically both groups had reduction in glucose levels but it was hard to determine if this was due to fasting or the intervention since glucose levels during the preoperative phase were random. It may also be important to determine the willingness of participants to make changes based on being a part of the pilot project. Most participants were excited to be a part of the project and wanted to determine what they could do to improve their surgical outcomes. The Hawthorne effect may have impacted the results of the findings since participants knew that they were involved in the pilot project that would be looking at glucose levels the day of surgery. Discussion of pilot project during the consent process could have made participants more aware of the need for controlling their glucose even if they did not receive the telephone education.

The number of patients with diabetes undergoing surgery will only increase as diabetes increases among the population. Patient education and awareness of potential postoperative complications of uncontrolled diabetes is key to obtaining better postoperative outcomes. Early intervention during the surgical process can help to provide patients with the needed time to make changes and work towards obtaining glycemic control during the preoperative period. The evidence supports the use of a 
GLUCOSE PRIOR TO SURGERY

telephone follow-up call. In addition, the clinical significance of this pilot project also provides evidence to support delaying non-emergent surgery until glycemic control is obtained. Although the results of this pilot project were non-significant it would be recommended to continue with the intervention but with the following modifications. The first recommendation would be for the patients to receive the intervention at least 2 weeks prior to the planned surgical intervention. This would give the patient time to make needed lifestyle changes. In addition, it would be recommended that only patients with $\mathrm{HgAl}$ c levels over $9 \%$ receive the intervention instead of $\mathrm{HgAlc}$ level over 7\%. Another option would be for those patients with HgAlc levels over 9\% to be contacted by the diabetes educators and/or referred to the PCP for medical evaluation and optimization of uncontrolled diabetes. Several non-emergent cases were not postponed in this pilot project. Recommendations would be made to surgeons to delay non-emergent cases until glycemic control is obtained. Delaying surgery may also motivate patients to make needed changes in order to improve surgical outcomes.

\section{Attainment of DNP Essentials}

\section{Essential I: Scientific Underpinning for Practice.}

Essential I was attained via completion of extensive literature review of current evidence, which was found to be supportive of practice change. The supportive evidence obtained from the literature was used to guide the practice change. Kotter's change model served as the theoretical framework for change.

Essential II: Organizational and Systems Leadership for Quality Improvement and Systems Thinking Essential II was attained by determining a need for improving the 
GLUCOSE PRIOR TO SURGERY

care of surgical patients with uncontrolled Type 2 diabetes. New delivery of care was piloted based upon current evidence, which was supportive of a telephone follow-up call. Measurable objectives were developed and analyzed upon completion of the pilot project. A budget plan was identified and financial impacts for the organization were determined and presented to management of WVUH. Advanced communication skills were utilized to gain approval and buy in for pilot project from leadership and staff in the preoperative evaluation center.

\section{Essential III: Clinical Scholarship and Analytical Methods for Evidence-Based \\ Practice}

Essential III was attained via translation of the current evidence into practice. Critical appraisal of the literature determined that a telephone follow-up call was an effective means of providing education for surgical patients with uncontrolled Type 2 diabetes. The knowledge gained via the literature review was applied to solve the practice problem of surgical patients with uncontrolled Type 2 diabetes. The evidence was supportive of a telephone follow-up call to help patients obtain better glycemic control, which will in turn help to improve patient outcomes. Data from pilot project was analyzed and results discussed. Findings from the pilot project will be disseminated by submitting findings for publication to professional journals.

\section{Essential IV: Information Systems/Technology and Patient Care Technology for the Improvement and Transformation of Health Care}

Essential IV was attained by designing and implementing pilot project to follow-up with surgical patients with uncontrolled Type 2 diabetes. Contacting patients via telephone and providing additional education for self-management of their disease demonstrates the 
GLUCOSE PRIOR TO SURGERY

use of technology in patient education. Outcomes were monitored and evaluated to determine effectiveness of pilot project. Data was extracted and analyzed from the pilot project, with the intention of disseminating findings.

\section{Essential V: Health Care Policy for Advocacy in Health Care}

Essential V was attained via analyzing current policy for care of surgical patients with Type 2 diabetes in the preoperative evaluation center. Evaluation of current policy determined that surgical patients with uncontrolled Type 2 diabetes were not being notified regarding the results of their $\mathrm{HgAlc}$ or the risk of poor surgical outcomes related to uncontrolled diabetes preoperatively. Based on this evaluation, the pilot project was initiated to determine if a telephone follow-up control would help to decrease day of surgery glucose levels. Education was provided to PAU staff on the impact of uncontrolled Type 2 diabetes on surgical outcomes along with their role in recruiting participants for the pilot project.

\section{Essential VI: Interprofessional Collaboration for Improving Patient and Population}

Health Outcomes Essential VI was attained by working collaboratively with several members of the health care team to initiate pilot project. There was collaboration with upper management from WVU Medicine and the research council to obtain approval for pilot project. Discussions about this pilot project took place with WVU Medicine administrators, managers, and PAU staff. Effective team leadership was used to gain buy-in and assistance from the staff in the PAU. Interprofessional collaboration among the RNs, APRNs, and MAs was critical for the success of the pilot project. Kotter's change process served as a guide for leading collaboration with staff of the PAU. 
GLUCOSE PRIOR TO SURGERY

\section{Essential VII: Clinical Prevention and Population Health for Improving the Nation's Health}

Essential VII was attained by working to develop an intervention to help surgical patients with uncontrolled Type 2 diabetes. The number of patients with diabetes is increasing and is expected to increase. Identifying ways to help surgical patients with Type 2 diabetes achieve glycemic control will help to improve surgical outcomes and prevent postoperative complications related to hyperglycemia. Dissemination of findings can help to improve care of surgical patients with Type 2 diabetes.

\section{Essential VIII: Advanced Nursing Practice}

Essential VIII was attained via designing, implementing, and evaluating a pilot project based on nursing science to determine and make recommendations regarding the care of surgical patients with uncontrolled Type 2 diabetes. Evidence based care was developed in order to improve surgical outcomes for patients with uncontrolled Type 2 diabetes. Staff was mentored, supported, and guided via Kotter's change process. Staff was provided with education and evidence to support pilot project and practice change. The development and implementation of this project, now being prepared for dissemination, through the course of the doctoral program is an example of how an individual APRN advances nursing practice. 


\title{
Appendix A
}

\author{
Capstone Budget Plan \\ Personal Funds \\ Organizational \\ Form and Justification \\ Contributions \\ List funds requested for \\ each category including a \\ reasonable justification for \\ expenses. Include total \\ amount of in-kind \\ contributions, if any, for \\ each category. Budget \\ Categories
ADMINISTRATIVE
$\$ 0$
$\$ 6,540.00$ \\ COSTS
}

Administrative Justification: Project leader@51.12/hour during project, no fringe since project leader does not get benefits and part of DNP capstone project. WVUH will donate all salaries for this project including time for education of the APRNs for the intervention. 100 capstone hours $x$ 51.12 $=\$ 5,112.00$. In addition, education for APRN 2 hours $x 12$ APRNs= \$1,200.00 (Average APRN salary \$50.00 an hour. Average salary for RN \$38.00 (2 lead RNs and 1 clinical preceptor) \$228.00 for their education. All time will be donated by WVUH. Time for telephone education of 25 patients will be donated as part of the DNP capstone project.

\section{MARKETING \$ 0 \$ 0}

Marketing Justification: No marketing needed since part of DNP project

EDUCATIONAL \$ \$ $\$$

MATERIALS/

INCENTIVES

Educational Materials/Incentives Justification: Equipment such as computers, fax, telephone, printer already provided by WVUH. Email is already set up as a form of additional communication with staff

HOSPITALITY (food, $\$ \mathbf{\$ 0 . 0 0} \$ \mathbf{\$ 0}$

room rentals, etc.)

Hospitality Justification: Meeting rooms will be supplied by WVUH. Cookie tray from Sam's club x 2.

PROJECT SUPPLIES $\$ \mathbf{\$ 5 0 . 0 0} \$ \mathbf{\$ 0}$

(office supplies, postage,

printing, etc.)

Project Supplies Justification: Additional \$30.00 for supplies needed such as paper to print consents.

TRAVEL EXPENSES \$ 0 \$ 0

Travel Expenses Justification: Travel will be to institution and will part of the DNP role

OTHER 
Other Justification: None

TOTALS
$\$ 90.00$
$\$ 6,540$

\section{Financial Plan \\ Detailed Budget Description:}

Initiation of a new intervention can be costly and it is important to analyze the cost of starting up a new intervention. Attached is the Capstone Budget Plan Form and Justification for initiation of APRN telephone follow-up call for patient with diabetes and elevated A1c greater than 7. The benefit of this intervention is that aside from staff time for education and completing telephone follow-up there is not really much additional cost taken for the unit aside from short term cost of supplies for nurse practitioner templates that will be used to guide the follow-up telephone call. There will be some cost associated with printing consents and other information needed for education. Average APRN salary at WVUH is $\$ 50.00$ per hour and the RN salary is $\$ 38.00$ per hour. In the preadmission testing area there are currently 13 nurse practitioner and 3 registered nurses (2 lead nurses and clinical preceptor) that work on the unit who would require education of the intervention. Education of nurse practitioners and other staff could also take place during weekly staff meetings, which time is already allotted by the organization. The lead nurse interventionist would be providing education of the staff as part of DNP Capstone project. It is important to make sure all staff are starting out at the same level, therefore a baseline education session will be provided and then move forward with the intervention. Once the intervention has been initiated, it will be important to look at the cost associated with the time spent by the nurse reviewing data and outcomes of the intervention. Implementation of this intervention will not only help to decrease cost of postoperative complications but also increase patient safety and improve patient care. Tight glycemic control of surgical patients needs to be addressed during the preoperative evaluation. Nurse practitioners in preadmission testing play a key role in educating patients and decreasing risk of postoperative complications. Although some short-term cost may be associated with the initiation of this project the long-term cost of treatment for postoperative complications such as far outweighs the initial short-term investment. 


\section{Appendix B}

\section{WVUMedicine}

July 8,2016

To Whom It May Concern:

As the manager of PAU I'm excited to lend my support for Christine Mott FNP-BC to implement her proposed Capstone Project at West Virginia University Hospitals Pre Admission Testing Unit. Christine has been instrumental in working with patients with diabetes in PAU and has worked with the endocrine

department to update medication guidelines. I know that she will continue to work to improve outcomes for patients with uncontrolled diabetes undergoing surgical intervention at WVUH. I'm writing this letter in support of Christine Mott's planned Capstone proposal to have an APRN telephone follow up call for patients with diabetes and HgA1c levels over 7 that are seen in PAU. The organization and leadership at WVUH fully support this Capstone project. Christine has proven to be a change leader in PAU and we are excited for her to continue to work with the staff to develop this change process. Christine has shared her SMART Work plan and we are looking forward to the initiation of this project and know it will have a positive impact on our surgical patients with uncontrolled diabetes at WVUH.

Sincerely,

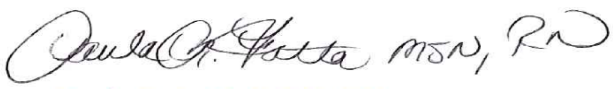

Paula R. Fotta MSN, RN

Perioperative Services Nurse Manager 2West Pre/Post and Preadmission Unit fottap@wvumedicine.org 304-598-4083

Portable Phone: 7-5727 


\section{Appendix C}

\begin{tabular}{|c|c|c|c|c|c|}
\hline \multicolumn{6}{|c|}{$\begin{array}{l}\text { Project Goals: The goal of the APRN led telephone intervention is to decrease blood } \\
\text { glucose levels during preoperative period, which in turn will result in decrease fasting } \\
\text { glucose day of surgery. }\end{array}$} \\
\hline $\begin{array}{l}\text { SMART } \\
\text { Objectives }\end{array}$ & Activities & $\begin{array}{l}\text { Projected } \\
\text { Completion } \\
\text { Date }\end{array}$ & $\begin{array}{l}\text { Projects } \\
\text { Number } \\
\text { of } \\
\text { People } \\
\text { Reached }\end{array}$ & $\begin{array}{l}\text { Organization/partners } \\
\text { collaborating with to } \\
\text { conduct activity }\end{array}$ & Evaluation Plan \\
\hline $\begin{array}{l}\text { By October } 3, \\
2016 \text { apply for } \\
\text { IRB approval } \\
\text { for a nurse } \\
\text { telephone } \\
\text { follow-up call } \\
\text { for patients with } \\
\text { Type } 2 \text { diabetes } \\
\text { and HgA1c } \\
\text { levels over } 7 \\
\text { undergoing } \\
\text { surgical } \\
\text { intervention at } \\
\text { Academic } \\
\text { Medical Center } \\
\text { in North Central } \\
\text { WV }\end{array}$ & $\begin{array}{l}\text { *Review proposal } \\
\text { with Dr. Mallow, } \\
\text { Dr. Barker, and } \\
\text { Renee } \\
\text { Schwertfeger } \\
\text { FNP-BC } \\
\text { *IRB protocol } \\
\text { completed and } \\
\text { submitted to IRB } \\
\text { *Meet and present } \\
\text { intervention to } \\
\text { IRB for approval }\end{array}$ & $\begin{array}{l}\text { October 3, } \\
2016\end{array}$ & 5 & $\begin{array}{l}\text { Academic Medical } \\
\text { Center in North } \\
\text { Central West } \\
\text { Virginia } \\
\text { PAU manager and } \\
\text { director } \\
\text { Surgeons and } \\
\text { anesthesia staff } \\
\text { NP and RNs in PAU }\end{array}$ & $\begin{array}{l}\text { Obtained final } \\
\text { approval on } \\
\text { proposed } \\
\text { Capstone from } \\
\text { committee } \\
\text { members } \\
\text { Obtained } \\
\text { approval of IRB }\end{array}$ \\
\hline $\begin{array}{l}\text { By October } 17, \\
2016 \text { secure } \\
\text { meeting room, } \\
\text { time, and date to } \\
\text { present } \\
\text { intervention to } \\
\text { key } \\
\text { stakeholders, } \\
\text { champions, and } \\
\text { assemble } \\
\text { coalition }\end{array}$ & $\begin{array}{l}\text { *Set up } \\
\text { conference room } \\
\text { at WVUH with } \\
\text { administrative } \\
\text { secretary to } \\
\text { determine time, } \\
\text { date, and location }\end{array}$ & $\begin{array}{l}\text { October } \\
17,2016\end{array}$ & 1 & $\begin{array}{l}\text { Academic Medical } \\
\text { Center in North } \\
\text { Central West } \\
\text { Virginia } \\
\text { Administrative } \\
\text { Assistant } \\
\text { PAU Manager }\end{array}$ & $\begin{array}{l}\text { Email from } \\
\text { administrative } \\
\text { secretary } \\
\text { confirming date, } \\
\text { time, and } \\
\text { location of } \\
\text { meeting }\end{array}$ \\
\hline $\begin{array}{l}\text { By October } 21, \\
2016 \text { handouts } \\
\text { and protocol } \\
\text { regarding }\end{array}$ & $\begin{array}{l}\text { *Print evidence } \\
\text { based articles } \\
\text { which show } \\
\text { telehealth as a }\end{array}$ & $\begin{array}{l}\text { October } \\
21,2016\end{array}$ & 20 & $\begin{array}{l}\text { Academic Medical } \\
\text { Center in North } \\
\text { Central West } \\
\text { Virginia }\end{array}$ & $\begin{array}{l}\text { Completed } \\
\text { information } \\
\text { Completed and }\end{array}$ \\
\hline
\end{tabular}


GLUCOSE PRIOR TO SURGERY

\begin{tabular}{|c|c|c|c|c|c|}
\hline $\begin{array}{l}\text { practice change } \\
\text { and information } \\
\text { will be put } \\
\text { together with } \\
\text { evidence for } \\
\text { practice change } \\
\text { utilizing } \\
\text { Kotter's change } \\
\text { model and } \\
\text { present clear } \\
\text { vision for } \\
\text { change }\end{array}$ & $\begin{array}{l}\text { success } \\
\text { intervention } \\
\text { *Print information } \\
\text { about when to } \\
\text { initiate } \\
\text { intervention } \\
\text { *Print out } 20 \\
\text { laminated } \\
\text { protocols as to } \\
\text { when to initiate } \\
\text { intervention and } \\
\text { what areas to } \\
\text { discuss with } \\
\text { patient }\end{array}$ & & & $\begin{array}{l}\text { PAU Manager } \\
\text { Administrative } \\
\text { Secretary } \\
\text { PAU nurses (lead } \\
\text { RNs and clinical } \\
\text { preceptor) and } \\
\text { APRNs in PAU }\end{array}$ & $\begin{array}{l}\text { laminated } \\
\text { protocols }\end{array}$ \\
\hline $\begin{array}{l}\text { By October 24, } \\
2016 \text { meet with } \\
\text { key stakeholders } \\
\text { and champions } \\
\text { to present } \\
\text { intervention } \\
\text { along with } \\
\text { evidence to } \\
\text { support } \\
\text { intervention and } \\
\text { establishing a } \\
\text { sense of urgency } \\
\text { for needed } \\
\text { change }\end{array}$ & $\begin{array}{l}\text { *Meet with } \\
\text { manager, } \\
\text { anesthesia chair, } \\
\text { director PAU, } \\
\text { PAU APRNs, } \\
\text { lead RNs, and } \\
\text { clinical preceptor } \\
\text { during which time } \\
\text { I will identify } \\
\text { criteria for } \\
\text { patients with } \\
\text { diabetes that will } \\
\text { be enrolled in the } \\
\text { project } \\
\text { *Meet with } \\
\text { anesthesia chair } \\
\text { *Send an attached } \\
\text { email outline of } \\
\text { intervention along } \\
\text { with supporting } \\
\text { evidence to } \\
\text { stakeholders and } \\
\text { champions prior } \\
\text { to meeting for } \\
\text { review }\end{array}$ & $\begin{array}{l}\text { October } \\
24,2016\end{array}$ & 50 & $\begin{array}{l}\text { Academic Medical } \\
\text { Center in North } \\
\text { Central West } \\
\text { Virginia } \\
\text { PAU manager and } \\
\text { director } \\
\text { Surgeons and } \\
\text { anesthesia staff } \\
\text { PAU RNs, clinical } \\
\text { preceptor, and } \\
\text { APRNs }\end{array}$ & $\begin{array}{l}\text { Emails } \\
\text { confirming } \\
\text { meeting from } \\
\text { key stakeholders } \\
\text { and champions } \\
\text { Agreement and } \\
\text { approval to } \\
\text { initiate planned } \\
\text { intervention } \\
\text { from key } \\
\text { stakeholders }\end{array}$ \\
\hline $\begin{array}{l}\text { By October 25, } \\
2016 \text { RNs } \\
\text { involved and }\end{array}$ & $\begin{array}{l}* \text { Send email } \\
\text { notification to the } \\
\text { PAU manager, }\end{array}$ & $\begin{array}{l}\text { October } \\
25,2016\end{array}$ & 20 & $\begin{array}{l}\text { Academic Medical } \\
\text { Center in North } \\
\text { Central West }\end{array}$ & $\begin{array}{l}\text { E mail from } \\
\text { PAU manger } \\
\text { with location, }\end{array}$ \\
\hline
\end{tabular}


GLUCOSE PRIOR TO SURGERY

\begin{tabular}{|c|c|c|c|c|c|}
\hline $\begin{array}{l}\text { nurse } \\
\text { practitioners } \\
\text { will be sent } \\
\text { email } \\
\text { notification of } \\
\text { their role in } \\
\text { implementation } \\
\text { of the } \\
\text { intervention and } \\
\text { be provided } \\
\text { with guidelines }\end{array}$ & $\begin{array}{l}\text { RNs and NPs } \\
\text { regarding dates, } \\
\text { times, and when } \\
\text { Capstone will } \\
\text { begin }\end{array}$ & & & $\begin{array}{l}\text { Virginia } \\
\text { PAU manager and } \\
\text { director } \\
\text { RNs, lead RNs, } \\
\text { clinical preceptor, } \\
\text { and NPs } \\
\text { Administrative } \\
\text { Secretary }\end{array}$ & $\begin{array}{l}\text { date, and times } \\
\text { Email from } \\
\text { manager, RNs, } \\
\text { and NPs } \\
\text { confirming } \\
\text { attendance }\end{array}$ \\
\hline $\begin{array}{l}\text { By November } 4 \text {, } \\
2016 \text { NP and } \\
\text { RNs in PAU } \\
\text { will be educated } \\
\text { and trained on } \\
\text { the intervention. } \\
\text { Handouts will } \\
\text { be administered } \\
\text { to staff along } \\
\text { with } \\
\text { empowering } \\
\text { staff to be a part } \\
\text { of the change } \\
\text { process. }\end{array}$ & $\begin{array}{l}\text { *Discussion of } \\
\text { intervention and } \\
\text { role of staff } \\
\text { *Handouts } \\
\text { delivered } \\
\text { *Laminated } \\
\text { protocols } \\
\text { delivered to NPs }\end{array}$ & $\begin{array}{l}\text { November } \\
4,2016\end{array}$ & 20 & $\begin{array}{l}\text { Academic Medical } \\
\text { Center in North } \\
\text { Central West } \\
\text { Virginia } \\
\text { PAU manager and } \\
\text { director } \\
\text { RNs, lead RNs, } \\
\text { clinical preceptor, } \\
\text { and NPs }\end{array}$ & $\begin{array}{l}\text { Evaluation of } \\
\text { intervention by } \\
\text { staff via verbal } \\
\text { feedback and } \\
\text { emails }\end{array}$ \\
\hline $\begin{array}{l}\text { On November } 7 \text {, } \\
2016 \text { APRNs in } \\
\text { PAU will start } \\
\text { utilizing } \\
\text { telephone } \\
\text { intervention on } \\
\text { all patients with } \\
\text { Type } 2 \text { diabetes } \\
\text { and HgA1c } \\
\text { levels over } 7\end{array}$ & $\begin{array}{l}\text { *Implementation } \\
\text { of intervention }\end{array}$ & $\begin{array}{l}\text { November } \\
7,2016\end{array}$ & 15 & $\begin{array}{l}\text { Academic Medical } \\
\text { Center in North } \\
\text { Central West } \\
\text { Virginia } \\
\text { PAU manager and } \\
\text { director } \\
\text { RNs, lead RNs, } \\
\text { clinical preceptor, } \\
\text { and NPs } \\
\text { Patients in PAU with } \\
\text { elevated HgA1c } \\
\text { levels over } 7\end{array}$ & $\begin{array}{l}\text { Documentation } \\
\text { regarding } \\
\text { implementation } \\
\text { of intervention } \\
\text { by the NP } \\
\text { In basket } \\
\text { notification sent } \\
\text { to project } \\
\text { manager of } \\
\text { those patients } \\
\text { that received the } \\
\text { follow-up phone } \\
\text { call }\end{array}$ \\
\hline $\begin{array}{l}\text { November } 14, \\
2016 \text { follow-up } \\
\text { with staff to } \\
\text { address any } \\
\text { issues with }\end{array}$ & $\begin{array}{l}\text { *Be present and } \\
\text { inquiry about any } \\
\text { issues or obstacles } \\
\text { *Send email to }\end{array}$ & $\begin{array}{l}\text { November } \\
14,2016\end{array}$ & 20 & $\begin{array}{l}\text { Academic Medical } \\
\text { Center in North } \\
\text { Central West } \\
\text { Virginia }\end{array}$ & $\begin{array}{l}\text { Email reply } \\
\text { from staff with } \\
\text { feedback and } \\
\text { suggestions }\end{array}$ \\
\hline
\end{tabular}


GLUCOSE PRIOR TO SURGERY

\begin{tabular}{|c|c|c|c|c|c|}
\hline $\begin{array}{l}\text { intervention, } \\
\text { resolve } \\
\text { obstacles and } \\
\text { celebrate small } \\
\text { wins }\end{array}$ & $\begin{array}{l}\text { staff requesting } \\
\text { feedback or any } \\
\text { suggestions for } \\
\text { improvement }\end{array}$ & & & $\begin{array}{l}\text { PAU manager and } \\
\text { director } \\
\text { RNs, lead RNs, } \\
\text { clinical preceptor, } \\
\text { and NPs }\end{array}$ & \\
\hline $\begin{array}{l}\text { By February 1, } \\
2017 \text { evaluation } \\
\text { of intervention } \\
\text { will be assessed } \\
\text { by looking at } \\
\text { fasting glucose } \\
\text { levels day of } \\
\text { surgery for } \\
\text { those patients } \\
\text { that received the } \\
\text { intervention and } \\
\text { those that were } \\
\text { the control }\end{array}$ & $\begin{array}{l}\text { *Chart review of } \\
\text { patients that } \\
\text { received } \\
\text { intervention } \\
\text { *Gather fasting } \\
\text { glucose levels am } \\
\text { of surgery for } \\
\text { intervention and } \\
\text { control group } \\
\text { *Review surveys } \\
\text { from staff } \\
\text { regarding } \\
\text { satisfaction with } \\
\text { education and the } \\
\text { change process }\end{array}$ & $\begin{array}{l}\text { February 1, } \\
2017\end{array}$ & 5 & $\begin{array}{l}\text { Academic Medical } \\
\text { Center in North } \\
\text { Central West } \\
\text { Virginia } \\
\text { PAU Manager } \\
\text { Academic Medical } \\
\text { Center in North } \\
\text { Central West } \\
\text { Virginia } \\
\text { PAU manager and } \\
\text { director } \\
\text { Surgeons and } \\
\text { anesthesia staff } \\
\text { PAU RNs, clinical } \\
\text { preceptor, and NPs }\end{array}$ & $\begin{array}{l}\text { Evaluation } \\
\text { summaries of } \\
\text { glucose levels } \\
\text { preop and } \\
\text { postop utilizing } \\
\text { paired test }\end{array}$ \\
\hline $\begin{array}{l}\text { By April 1, } \\
2017 \text { complete } \\
\text { data analysis, } \\
\text { assessment of } \\
\text { Kotter's practice } \\
\text { change and } \\
\text { Capstone final } \\
\text { paper completed } \\
\text { and corrections } \\
\text { made }\end{array}$ & $\begin{array}{l}\text { *Evaluation of the } \\
\text { change process in } \\
\text { PAU and the } \\
\text { effectiveness of } \\
\text { Kotter's change } \\
\text { model in PAU } \\
\text { *Identification } \\
\text { and analysis of } \\
\text { intervention via } \\
\text { data and statistical } \\
\text { significance from } \\
\text { intervention and } \\
\text { control group } \\
\text { *Final Capstone }\end{array}$ & $\begin{array}{l}\text { April 1, } \\
2017\end{array}$ & 20 & $\begin{array}{l}\text { Academic Medical } \\
\text { Center in North } \\
\text { Central West } \\
\text { Virginia } \\
\text { PAU manager and } \\
\text { director } \\
\text { Surgeons and } \\
\text { anesthesia staff } \\
\text { PAU RNs, clinical } \\
\text { preceptor, and NPs }\end{array}$ & $\begin{array}{l}\text { Statistical } \\
\text { analysis of } \\
\text { evidence from } \\
\text { the intervention } \\
n=25 \text { and } \\
\text { control group } \\
n=25 \\
\text { Assessment of } \\
\text { impact of } \\
\text { Kotter's practice } \\
\text { change via } \\
\text { survey for } \\
\text { APRNs } \\
\text { Final completed }\end{array}$ \\
\hline
\end{tabular}


GLUCOSE PRIOR TO SURGERY

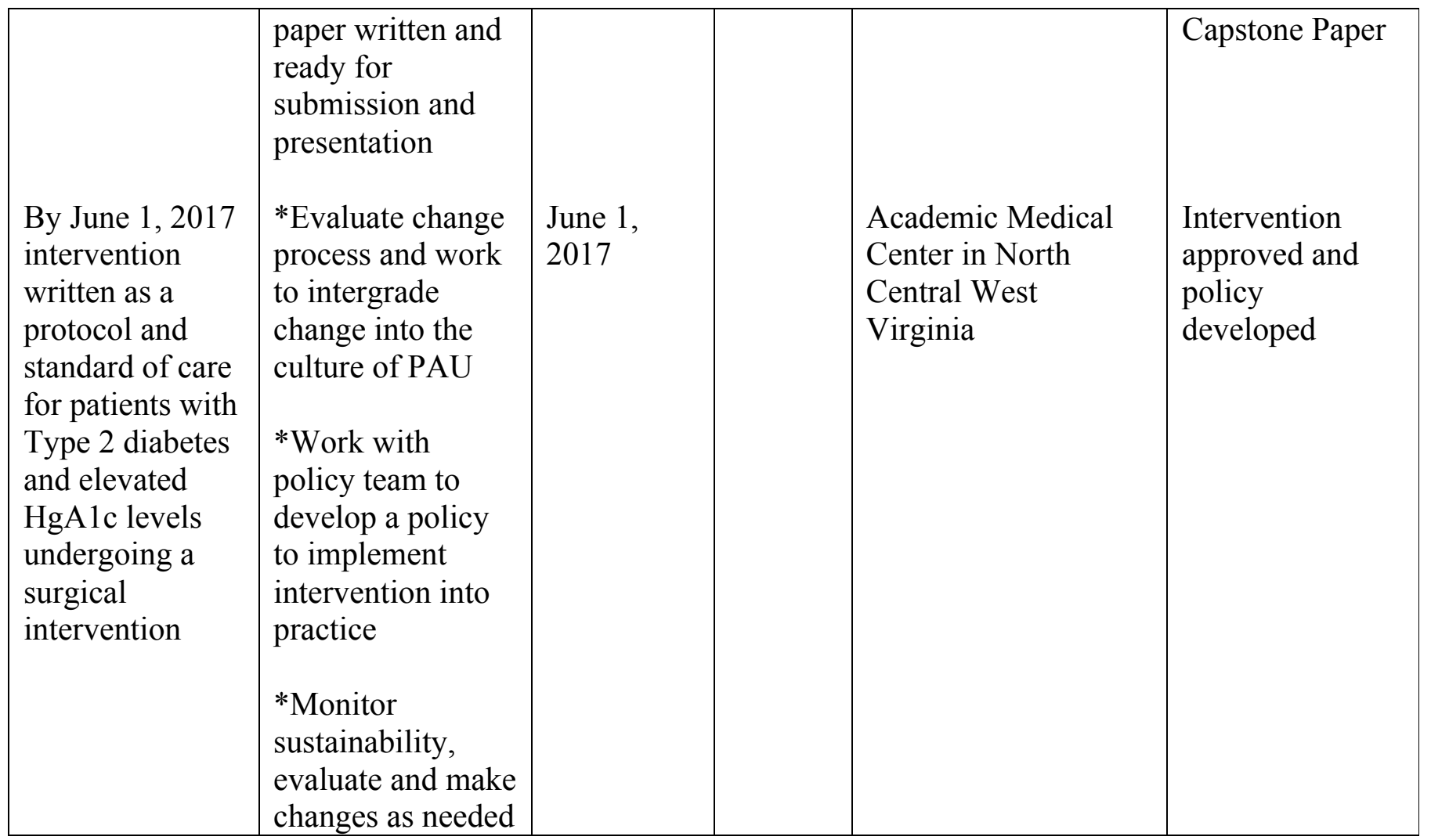




\section{Appendix D}

Hello. My name is and I'm one of the nurse practitioners at WVU Medicine. I was calling to follow-up with you about the lab work that you had done at you pre admission testing visit. I would like to spend a few minutes talking with you about your blood glucose and diabetes. Your HgA1c was , which means over the past 2-3 months your blood glucose has averaged around The American Diabetes Association recommends that your HgA1c level be less than 7\%. Even though your $\mathrm{HgA} 1 \mathrm{c}$ was higher than $7 \%$, there are still things that you can do leading up to surgery to help bring down you glucose levels. It is really important to control your glucose leading up to surgery and after surgery. Having high blood glucose can put you at a higher risk for developing an infection and also delay healing from your surgery. There are many things that you can do to help better control your daily blood glucose levels, and I will briefly cover seven important topics that will help you in this process.

The first two topics are Monitoring of blood glucose/Problem Solving:

It is very important that you monitor you blood glucose before and after surgery to make sure you are staying on track and see what changes are working. We want you to regularly check your glucose levels leading up to surgery so you can see what is and is not working. If you don't check the levels than you will not know what works best for you. Our goal the day of surgery would be for your glucose levels to be between 90-130. Even getting your glucose closer to this range will help so don't feel defeated if you don't reach this goal yet.

Problem solving: It will be important for you to feel comfortable making decisions about how you handle your diabetes. If you become unsure and about what to do you can always contact your PCP or even call 304-598-6100 and a nurse can help you to make decisions regarding your glucose levels and management.

On the day of surgery we want you to check you glucose levels and monitor them closely, especially if you are feel that your blood glucose is getting too low (symptoms may include confusion, heart palpitations, shakiness, nausea, headache, and anxiety). Do you know what low blood sugar feels like? Do you know what to do the day of surgery if your glucose level gets below 60 ?

The next topic is Medication Adherence:

It is very important that you take your medications as instructed prior to surgery. Skipping even one dose can have an impact on your glucose levels. The nurse practitioner in pre admission testing should have instructed you about what medications you can and can not take the morning of surgery. Do you have any questions about what you need to do with your diabetes medications on the day of surgery? 
An additional topic that will help you before and after surgery is to practice Healthy

\section{Eating}

- Count carbohydrates (also called carbs). Carbs - are foods like bread, rice, crackers, cereal, fruit, juice, milk, yogurt, potatoes, corn, peas, sweets - and these foods raise your blood glucose levels the most. It is important to keep the amount of carbs in your meals and snacks about the same from day to day to help you reach your blood glucose targets. You may already know what foods will cause your blood glucose to be higher. Try to avoid those foods or eat them in moderation.

- Choose foods low in saturated fat. Cut down on foods with saturated fat to help you lower your cholesterol and prevent heart disease. Foods high in saturated fat include meats, butter, whole milk, cream, cheese, lard, shortening, many baked goods, and tropical oils such as palm and coconut oil.

- Lower portion sizes. Cutting back on food portions at meals and snacks can help with weight loss and decrease glucose.

- Eat more fiber. Eat more high-fiber foods such as fruits, vegetables, dried beans and peas, oatmeal, and whole grain breads. This will be important especially before surgery because the anesthesia can slow down your digestion and cause constipation. If you are going to be taking pain medications after your surgery this can also contribute to constipation.

One of the final topics to cover is your level of Physical Activity. One way to help control blood glucose is to increase your physical activity. Do you have any current restrictions on your activity? If not think about small things that you can do daily to increase the amount of physical activity you get. It can be taking the stairs or walking around your home. Increasing activity can help to decrease your glucose levels.

The last topic that I want to cover with you is Healthy Coping:

Having surgery can be very stressful for patients. We know that this can increase blood glucose levels. Do you feel stressed or anxious regarding your upcoming surgery? If so there are some things you can do help decrease your anxiety. It is important to talk about your concerns either with family, friends, or your health care provider. Having concerns addressed and answers to question can help to make you feel more comfortable. Trying relaxation techniques such as slow and deep breathing can also help. Think about how you have handled anxiety and stress in the past and apply those techniques. Are there any questions that you would like to ask me?

I would like to wrap up by reiterating that not only is it important to control your glucose before and after surgery but also to control your diabetes in the future to prevent other serious complications such as heart attack, strokes, nerve disease, kidney disease, blindness, and amputations. You may also want to talk with your primary care provider 
about gaining better control of your diabetes. WVUH has many resources that can help you manage your diabetes if you are interested. We have a department of endocrinology that focuses specifically on helping patients with diabetes and also a diabetes education center. Here you can learn more about diabetes and how you can better manage your diabetes. If you are interested I can give you those phone numbers or I can send your information to the diabetes educators and they will contact you.

WVU Diabetes Education Center 304-598-4391

WVU Endocrine 304-588-4865 


\section{Appendix E}

\section{Table 1 Demographics}

\begin{tabular}{|c|c|c|c|c|c|}
\hline \multicolumn{6}{|c|}{ Gender } \\
\hline & & Frequency & Percent & Valid Percent & $\begin{array}{c}\text { Cumulative } \\
\text { Percent }\end{array}$ \\
\hline \multirow[t]{3}{*}{ Valid } & $\mathrm{F}$ & 28 & 56.0 & 56.0 & 56.0 \\
\hline & $\mathrm{M}$ & 22 & 44.0 & 44.0 & 100.0 \\
\hline & Total & 50 & 100.0 & 100.0 & \\
\hline
\end{tabular}

\begin{tabular}{|c|c|c|c|c|c|}
\hline \multicolumn{6}{|c|}{ Ethnicity } \\
\hline & & Frequency & Percent & Valid Percent & $\begin{array}{c}\text { Cumulative } \\
\text { Percent }\end{array}$ \\
\hline Valid & White & 50 & 100.0 & 100.0 & 100.0 \\
\hline
\end{tabular}

\begin{tabular}{ll|r|r|r|r}
\multicolumn{2}{c}{ Marital Status } & & \multicolumn{2}{c}{$\begin{array}{c}\text { Cumulative } \\
\text { Percent }\end{array}$} \\
\hline Valid & Frequency & Percent & Valid Percent & 10.0 \\
\cline { 2 - 6 } & Divorced & 5 & 10.0 & 10.0 & 70.0 \\
\cline { 2 - 6 } & Married & 30 & 60.0 & 60.0 & 72.0 \\
\hline Separated & 1 & 2.0 & 2.0 & 74.0 \\
\hline Significant other & 1 & 2.0 & 2.0 & 88.0 \\
\hline Single & 7 & 14.0 & 14.0 & 100.0 \\
\hline Widowed & 6 & 12.0 & 12.0 & \\
\hline Total & 50 & 100.0 & 100.0 & \\
\hline
\end{tabular}


Table 2

\section{Descriptive Continuous Data Both Groups}

\begin{tabular}{lr|r|r|r|r}
\multicolumn{7}{c}{ Descriptive Statistics } & \\
& $N$ & Minimum & Maximum & Mean & Std. Deviation \\
\hline Pre Glucose & 50 & 155 & 429 & 248.52 & 68.164 \\
\hline Post Glucose & 46 & 74 & 334 & 169.74 & 56.648 \\
\hline A1C & 50 & 7.20 & 13.80 & 9.1820 & 1.62816 \\
\hline Age & 50 & 29 & 79 & 53.64 & 10.836 \\
\hline BMI & 50 & 24 & 74 & 37.06 & 8.497 \\
\hline Valid N (list wise) & 46 & & & & \\
\hline
\end{tabular}

\section{Table 3}

\section{ANOVA}

\section{Test of Homogeneity of Variances}

Post Glucose

\begin{tabular}{|c|c|c|c|}
\hline Levene Statistic & df1 & $\mathrm{df} 2$ & Sig. \\
\hline .187 & 1 & 44 & .667 \\
\hline
\end{tabular}




\section{Table 4}

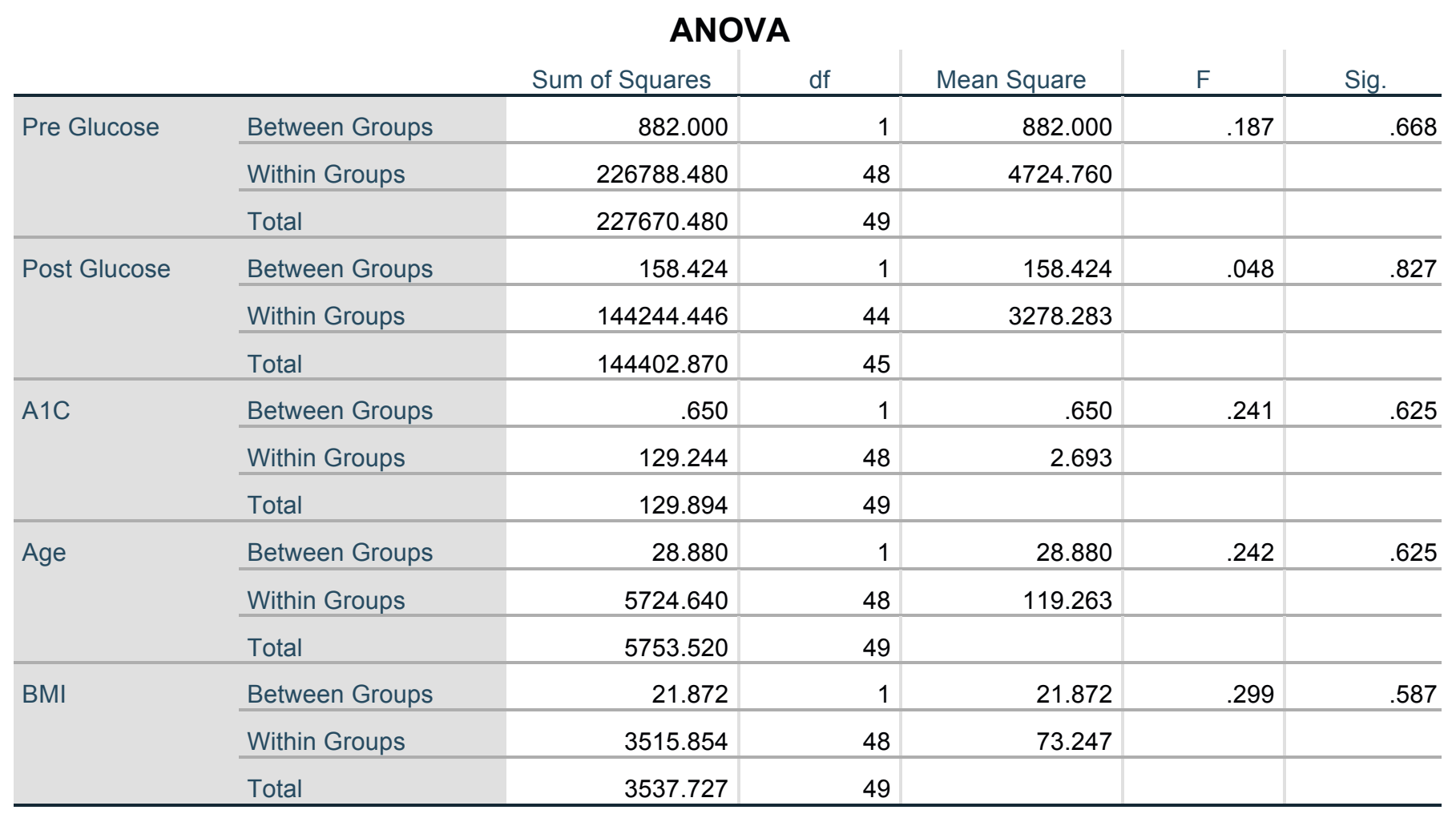




\section{References}

Aliha, J., Asgari, M., Khayeri, F., Ramazani, M., Farajzadegan, Z., \& Javahen, J. (2013). Group education and nurse-telephone follow-up effects on blood glucose control and adherence to treatment in Type 2 diabetes patients. International Journal of Preventive Medicine, 4, 797-802.

American Association of Diabetes Educators (2014). Position Statement American Association of Diabetes Educators 7 Self-Care Behaviors. Retrieved from https://www.diabeteseducator.org/patient-resources/aade7-self-care-behaviors

American Diabetes Association (2016). Standards of medical care in diabetes-2016. Diabetes Care, 39. Retrieved from www.diabetes.org/diabetescare

Bakken, S. (2006). Informatics for patient safety: a nursing research perspective. Annual Review of Nursing Research, 24, 219-254.

Bell, A., Fonda, S., Walker, S., Schmidt, V., \& Vigersky, R. (2012). Mobile phone-based video messages for diabetes self-care support. Journal of Diabetes Science and Technology, 6, 310-319. Retrieved from http:www.ncbi.nlm.gov/pmc/articles/PMC3380772/

Cavanaugh, K. L. (2011). Health literacy in diabetes care: explanation, evidence, and equipment. Diabetes Management, 191-199.

Centers for Disease Control and Prevention. (2015). Health, United States, 2015. Retrieved from Center for Disease Control and Prevention: http://www.cdc.gov/nchs/data/hus/hus15.pdf\#040 
GLUCOSE PRIOR TO SURGERY

Center for Disease Control and Prevention (2011). Press Release: more than a third of adults estimated to have prediabetes, 2011. Atlanta, GA: U.S. Department of Health and Human Services, Center for Disease Control and Prevention.

Coyne, C., Demian-Popescu, C., \& Friend, D. (2006). Social and cultural factors influencing health in southern West Virginia: A qualitative study. Preventing Chronic Disease, 3.

Davis, K. (2016, July12). Personal interview.

Fotta, P. (2016, July 7). Personal interview.

Foulk, D., Carroli, P., \& Wood, S. (2001). Addressing health literacy: A description of the intersection of functional literacy and health care. American Journal of Health Studies, 17.

Frosch, D., Uy, V., Ochoa, S., \& Mangione, C. (2011, December 12). Evaluation of a behavior support intervention for patients with poorly controlled diabetes. Arch Intern Med, 171, 2011-2017. doi: 10.1001/archinternmed.2011.497

Garg, R., Metzger, C., Rein, R., Lortie, M., Underwood, P., Hurwitz, S.,...Schuman, B. (2016). Nurse practitioner-mediated intervention for preoperative control of diabetes in elective surgery patients. Journal of the American Association of Nurse Practitioners, 1-6.

Gray, P., Drayton-Brooks, S., \& Williamson, K. (2013). Diabetes follow-up support for patients with uncontrolled diabetes. The Nurse Practitioner, 49-53.

Graziano, J., \& Gross, C. (2009). A randomized controlled trial of an automated telephone intervention to improve glycemic control in Type 2 diabetes. Advances in Nursing Science, 32, 42-57. doi: 10.1097/ANS.0b013e3181b117a9 
GLUCOSE PRIOR TO SURGERY

Health Resources and Services Administration. (2016). What is telehealth? Retrieved from http://www.hrsa.gov/healthit/toolbox/RuralHealthITtoolbox/Telehealth/whatistele health.html

Hebda, T., \& Czar, P. (2012). Handbook of informatics for nurses \& healthcare professionals (5th ed.). New Jersey: Pearson.

Kaiser Family Foundation. (2014, September 1). Health Coverage \& Uninsured Indicators. Retrieved September 1, 2014, from http://kff.org/statecategory/health-coverage-uninsured/

Khunit, K., Gray, L., Skinner, T., Carey, M., Realf, K., Dallosso, H.,...Davies, M. (2012). Effectiveness of a diabetes education and self management programme for people with newly diagnosed Type 2 diabetes mellitus: three year follow-up of a cluster randomised controlled trial in primary care. British Medical Journal, 1-12. doi:

http://dx.doi.org/10.1136/bmj.e2333

Killilea, T. (2002). Long-term consequences of Type 2 diabetes mellitus: economic impact on society and managed care. American Journal of Managed Care, 8, 441449. Retrieved from www.ncbi.nim.nih.gov/pubmed/12408407

Kim, H. (2007). A randomized controlled trial of a nurse short-message service by cellular phone for people with diabetes. International Journal of Nursing Studies, 44, 687-692. doi: 10.1016/j.ijnurstu.2006.01.011

Kirkland, K., Briggs, J., Trivette, S., Wilkinson, W., \& Sexton, D. (1999). The impact of surgical site infections in the 1990s: attributable mortality, excess length of 
GLUCOSE PRIOR TO SURGERY

hospitalization, and extra costs. Infect Control Hosp Epidemiol, 725-30. Retrieved from http://www.ncbi.nim.nih.gov/pubmed/10580621

Kotter, J. (1996). Leading change. Boston, Massachusetts: Harvard Business Review Press.

Larrabee, J.H. (2009). Nurse to Nurse: Evidence Based Practice Expert Interventions. New York, NY: McGraw Hill.

Lee, G., Wyatt, S., Topliss, D., Walker, K., \& Stoney, R. (2014). A study of a preoperative intervention in patients with diabetes undergoing cardiac surgery. Elsevier, 287-293. doi: doi.org/10.1016/j.colegn.2013.06.001

Loh-Trivedi, M. (2011). Perioperative Management of the Diabetic Patient. Medscape. Advance online publication. Retrieved from http://emedicine.medscape.com/article/284451-overview

McMahon, G., Fonda, S., Gomes, H., Alexis, G., \& Conlin, P. (2012, November 11). A randomized comparison of online and telephone based care management with internet training alone in adult patients with poorly controlled Type 2 diabetes. Diabetes Technology \& Therapeutics, 14, 1060-7. doi: 10.1089/dia.2012.0137

Moitra, V. K., \& Meiler, S. E. (2006). The diabetic surgical patient. Current Opinion in Anesthesiology, 19, 339-345. Retrieved from www.ncbi.nim.nih.gov/pubmed/16735820

National Guideline Clearinghouse (NGC). Guideline summary: [Steps to reduce surgical risk. In: II guidelines for perioperative evaluation]. In: National Guideline Clearinghouse (NGC) [U.S. Department of Health \& Human Services]. Rockville (MD): Agency for Healthcare Research and Quality (AHRQ); [cited 06/02/2016]. 
GLUCOSE PRIOR TO SURGERY

Available:

https://www.guideline.gov/content.aspx?id=34057\&search=a1c+level+for+surger

$\mathrm{y}$

Nesari, M., Zakerimoghadam, M., Rajab, A., Bassampour, S., \& Faghihzadeh, S. (2010). Effect of telephone follow-up on adherence to a diabetes therapeutic regimen. Japan Journal of Nursing Science, 7, 121-128. doi: 10.1111/j.17427924.2010.00146.x

Orem, D. E. (2001). Nursing: Concepts of practice (6th ed.). St. Louis: Mosby.

Pare, G., Moqadem, K., Pineau, G., \& St-Hilaire, C. (2010, June 16). Clinical effects of home telemonitoring in the context of diabetes, asthma, heart failure and hypertension: A systematic review. Journal of Medical Internet Research , 1-23. doi: 10.2196/jmir.1357

Perencevich, E., Sands, K., Cosgrove, S., Guadagnoli, E., Meara, E., \& Platt, R. (2003). Health and economic impact of surgical site infections diagnosed after hospital discharge. Emerg Infect Dis, 196-203. Retrieved from http://www.ncbi.nim.nih.gov/pubmed/12603990

Plodkowski, R., \& Edelman, S. (2001). Pre-surgical evaluation of diabetic patients. Clinical Diabetes, 19, 92-95. Retrieved from http://dx.doi.org/10.2337/diaclin.19.2.92

Polk, H., \& Christmas, A. (2000). Prophylactic antibiotics in surgery and surgical wound infections. American Journal of Surgery, 2, 105-11. Retrieved from http://www.ncbi.nim.nih.gov/pubmed/10695738 
Sacco, W., Malone, J., Morrison, A., Friedman, A., \& Wells, K. (2009, April 14). Effects of a brief, regular telephone intervention by paraprofessionals for Type 2 diabetes. Journal of Behavioral Medicine, 32, 349-359. doi: 10.1007/s10865-009-9209-4

Scottish Intercollegiate Guidelines Network. (2013). Critical appraisal: Notes and checklists. Retrieved from http://www.sign.ac.uk/methodology/checklists.html

Shepard, J., Ward, W., Milstone, A., Carlson, T., Frederick, J., Hadhazy, E., \& Perl, T. (2013). Financial impact of surgical site infections on hospitals. JAMA, 907-914. doi: 10.1001/jamasurg.2013.2246

Siriwardena, N., Wickramasinghe, S., Perera, D., Marasinghe, R., Katulanda, P., \& Hewapathirana, R. (2012). A review of telemedicine interventions in diabetes care. Journal of Telemedicine and Telecare, 18, 164-168. doi: 10.1258/jtt.2012.SFT110

Slusher, I., Withrow-Fletcher, C., \& Hauser-Whitaker, M. (2010). Appalachian women: Health beliefs, self-care, and basic conditioning factors. Journal of Cultural Diversity, 17, 84-89.

Smith, S., \& Tessaro, I. (2005). Cultural perspectives on diabetes in an Appalachian population. American Journal of Health Behavior, 29, 291-301.

Taylor, N. (2016). SWOT analysis: What it is and when to use it. Business News Daily. Retrieved from businessneswsdaily.com

Tessaro, I., Smith, S., \& Rye, S. (2005). Knowledge and perceptions of diabetes in an Appalachian population. Preventing Chronic Disease, 2(2). Retrieved from http://www.ncbi.nlm.nih.gov/pmc/articles/PMC1327707/ 
GLUCOSE PRIOR TO SURGERY

Underwood, P., Askari, R., Hurwitz, S., Chamarthi, B., \& Garg, R. (2014). Preoperative A1c and clinical outcomes in patients with diabetes undergoing major noncardiac surgical procedures. Diabetes Care, 611-616. Retrieved from http://dx.doi.org./10.2337/dc13-1929

U.S. Census Bureau. (2013). West Virginia Quick Facts. Retrieved September 1, 2014, from http://quickfacts.census.gov/qfd/states/54000.html WV

Walker, E., Shmukler, C., Ullman, R., Blanco, E., Scollan-Koliopoulus, M., \& Cohen, H. (2011). Result of a successful telephonic intervention to improve diabetes control in urban adults. Diabetes Care, 34, 2-7. doi: 10.2337/dc10-1005

West Virginia Department of Health \& Human Resources. (2009). The burden of diabetes in West Virginia 2009. Retrieved from : http://www.wvdhhr.org/bph/hsc/pubs/other/burdenofdiabetes2009/diabetes_burde n_mort_2010.pdf

West Virginia University Healthcare (2012). WVU healthcare strategic plan. Retrieved from http://www.hsc.wvu.edu/hsc2020/MediaLibraries/HSC2020/Media/Documents/H SC-Plans/WVUHealthcareStrategicPlan.pdf

Williams, E., Bird, D., Forbes, A., Russell, A., Ash, S., Friedman, R.,...Oldenburg, B. (2012). Randomised controlled trial of an automated interactive telephone intervention (TLC Diabetes) to improve Type 2 diabetes management: baseline findings and six-month outcomes. BMC Public Health. doi: 10.1186/1471-2458$12-602$ 
Wolever, R., Dreusicke, M., Hawkins, T., Yeung, S., Walkfield, J., Duda, L.,...Sinner, E. (2010). Integrative health coaching for patients with Type 2 diabetes. The Diabetes Educator, 36, 629-638.

Yoon, K., \& Kim, H. (2008). A short message service by cellular phone in Type 2 diabetes patients for 12 months. Diabetes Research And Clinical Practice, 79, 256-261. doi: 10.1016/j.diabres.2007.09.007

Zhan, C., \& Miller, M. (2003). Excess length of stay, charges and mortality attributable to medical injuries during hospitalization. $J A M A, 1868-1874$. Retrieved from http://www.ncbi.nlm.nih.gov/pubmed/14532315

Zolfaghari, M., Mousavifar, S., Pedram, S., \& Haghani, H. (2011). The impact of nurse short message services and telephone follow-ups on diabetic adherence: which one is more effective? Journal of Clinical Nursing, 21, 1922-1931. doi:

10.1111/j.1365-2702.0211.03951.x 